\title{
Computational Study of Hydrogen Direct Injection for Internal Combustion Engines
}

\author{
A. Hamzehloo and P.G. Aleiferis \\ University College London, UK
}

Copyright () 2012 SAE International

\section{ABSTRACT}

Hydrogen has been largely proposed as a possible fuel for internal combustion engines. The main advantage of burning hydrogen is the absence of carbon-based tailpipe emissions. Hydrogen's wide flammability also offers the advantage of very lean combustion and higher engine efficiency than conventional carbon-based fuels. In order to avoid abnormal combustion modes like pre-ignition and backfiring, as well as air displacement from hydrogen's large injected volume per cycle, direct injection of hydrogen after intake valve closure is the preferred mixture preparation method for hydrogen engines. The current work focused on computational studies of hydrogen injection and mixture formation for direct-injection spark-ignition engines. Hydrogen conditions at the injector's nozzle exit are typically sonic. Initially the characteristics of under-expanded sonic hydrogen jets were investigated in a quiescent environment using both Reynolds-Averaged NavierStokes (RANS) and Large-Eddy Simulation (LES) techniques. Various injection conditions were studied, including a reference case from the literature. Different nozzle geometries were investigated, including a straight nozzle with fixed cross section and a stepped nozzle design. LES captured details of the expansion shocks better than RANS and demonstrated several aspects of hydrogen's injection and mixing. Incylinder simulations were also performed with a side 6-hole injector using 70 and 100 bar injection pressure. Injection timing was set to just after inlet valve closure with duration of $6 \mu \mathrm{s}$ and $8 \mu \mathrm{s}$, leading to global air-to-fuel equivalence ratios $\phi$ typically in the region of $0.2-0.4$. The engine intake air pressure was set to 1.5 bar absolute to mimic boosted operation. It was observed that hydrogen jet wall impingement was always prominent. Comparison with non-fuelled engine conditions demonstrated the degree of momentum exchange between in-cylinder hydrogen injection and air motion. LES highlighted details of hydrogen's spatial distribution throughout the injection duration and up to ignition timing. Higher peak velocities were predicted by LES, especially on the tumble plane. With the employed injection strategy, the areas closer to the cylinder wall were richer in fuel than the centre of the chamber close to the end of compression.

\section{INTRODUCTION}

Current increases in cost of fossil energy carriers, as well as international obligations to reduce $\mathrm{CO}_{2}$ emission due to concerns about climate change, emphasize the importance of investigating alternative sources of energy. The concept of a wide hydrogen economy has been proposed since the mid1970s [1]. As a fuel for internal combustion (IC) engines, hydrogen has been recommended as a possible replacement for the current fossil fuels as it can be burnt in conventional engines without producing carbon-based emissions $[1,2]$. It has a wide range of flammability $[3,4]$ that allows engines to operate very lean and at high efficiency. This can also lead to greatly reduced $\mathrm{NO}_{\mathrm{X}}$ emissions at equivalence ratios lower than about 0.5 [5-7]. In order to eliminate hydrogen abnormal combustion modes such as pre-ignition and backfiring [8-10], injecting hydrogen directly into the combustion chamber (DI) after intake valves closure (IVC) has been proposed as a more suitable strategy in comparison to port fuel injection (PFI). Furthermore, closed-valve hydrogen DI eliminates issues related to air displacement from hydrogen's need of large injection durations due to its low density [11-14]. It also provides great flexibility in optimising the engine's mixture formation, performance and emission characteristics through various injection strategies, including timing and duration of injection, injection pressure, injector location and nozzle configurations [15-17].

Apart from injection strategy, intake air boosting can also have direct effects on the performance and efficiency of hydrogen-fuelled IC engines. Supercharging has been suggested as a promising possibility to increase the power output mainly in PFI hydrogen engines [18-25]. The idea of a boosted PFI hydrogen engine has been shown since the 1980s [18-20]. More recently, Berckmüller et al. [21] applied supercharging (1.8 bar) to increase the specific power output of a single-cylinder PFI engine by $30 \%$ in comparison to naturally aspirated operation. Al-Baghdadi and Al-Janabi [22] investigated the effects of compression ratio, equivalence ratio, and inlet pressure on the performance and $\mathrm{NO}_{\mathrm{X}}$ emissions of a carburetted supercharged hydrogen engine using quasi 1D modelling. Supercharging was found to be a 
more effective method of increasing the output of a hydrogen engine rather than increasing its compression ratio. Verhelst and Sierens [23] investigated two combustion strategies, leanburn and stoichiometric with variable Exhaust Gas Recirculation (EGR). Lean-burn was found to be better for low-load conditions than EGR, whilst for mid-load both strategies were found very similar in terms of indicated power and efficiency. However, $\mathrm{NO}_{\mathrm{X}}$ emissions were higher for the lean-burn strategy at all conditions. Finally they proposed a combination of EGR and inlet charge boosting (supercharging) to obtain the same power output for hydrogen engines as for identical gasoline ones, while maintaining very low $\mathrm{NO}_{\mathrm{X}}$ emissions. A PFI single-cylinder hydrogen engine was supercharged by Verhelst $e t a l$. [24] and it was found that stoichiometric mixtures when combined with EGR resulted in power output of up to $30 \%$ higher when compared to gasoline operation (although at lower efficiency compared to leanburn). Wallner et al. [25] studied a supercharged four-cylinder hydrogen engine on the usual urban drive cycle. Based on fuel consumption and $\mathrm{NO}_{\mathrm{X}}$ emissions, Wallner et al. [25] proposed a shift-gear strategy to optimize fuel economy based on a variable air/fuel strategy. It was also found that efficiency increased by about $1-2 \%$ when the air/fuel ratio was increased from $\lambda=2$ to $\lambda=3$ within low-load to high-load operation conditions; $\mathrm{NO}_{\mathrm{X}}$ emissions also showed beneficial effects as they decreased exponentially when air/fuel ratio increased from $\lambda=2.25$ to $\lambda=3$. In a series of experimental studies, Roy $e t$ al. [26-28] investigated performance and emission characteristics of a supercharged engine fuelled by hydrogen and mixtures of hydrogen with various other fuels. A pilot injection (Diesel) ignition process was used at the end of the compression stroke. Maximum thermal efficiency of the engine increased with the increase in hydrogen content in the fuels, especially in leaner operations, and neat hydrogen operation produced the highest thermal efficiency, about $13 \%$ higher than other fuels.

The majority of published work on boosted hydrogen engines has focused on PFI operation. However, increasing the charge pressure and temperature without careful intercooling can intensify the problems of abnormal combustion and $\mathrm{NO}_{\mathrm{X}}$ formation with PFI. Combination of boosted operation with DI can be adopted in hydrogen engines to obtain large power output with lean mixtures but very few studies can be found in the literature. Ohira et al. [29] investigated experimentally the emission characteristics of a hydrogen DI engine using different levels of boost pressure and air-to-fuel ratio. Hydrogen was injected at 70 bar and intake pressure was raised up to 8 bar. At intake manifold of 1.5 bar (fully open throttle) it was found that decreasing $\lambda$ from 2.8 to 1.8 led to an increase of $\sim 4$ bar in Brake Mean Effective Pressure (BMEP). In order to maintain $\mathrm{NO}_{\mathrm{X}}$ to level lower than 10 ppm, it was found that $\lambda$ must be kept at 2.4 or higher. In the same publication, Ohira et al. [29] also investigated different injection timings by means of Reynolds Averaged Navier Stokes (RANS) modelling. Their results highlighted difficulties in air-hydrogen mixing process predictions and the need for new CFD simulations; this conclusion was also based on Particle Image Velocimetry (PIV) measurements of the growth of hydrogen jets in the same paper. Nakagawa et al. [30] recently investigated the potential of achieving high power output, high thermal efficiency and near-zero $\mathrm{NO}_{\mathrm{X}}$ emissions by means of supercharged DI. It was reported that at the same BMEP the levels of $\mathrm{NO}_{\mathrm{X}}$ became lower as the intake air pressure increased. They obtained a maximum brake thermal efficiency of $34 \%$ at intake air pressure of 2 bar.

It is clear that fundamental understanding of the interaction between hydrogen's in-cylinder jets and in-cylinder air flow is essential for optimizing the mixture formation and combustion processes with either normal aspiration or boosting. However, studying injection processes with hydrogen fuelling is more complex than with liquid fuels or other gases, both experimentally and computationally. For example, hydrogen injection leads to sonic conditions at the nozzle that require significant computing time to resolve temporally and spatially. Additionally, hydrogen's specific nature means that it cannot be easily imaged and quantified in terms of concentration by 'standard' optical techniques, therefore increased cost and significant effort is needed to perform successful investigations.

The effects of fuel injection pressure and ambient density on the characteristics of hydrogen jets were investigated by Roy et al. [3] using high-speed imaging in a constant volume chamber using a pressure-swirl atomiser. In a research conducted by Wallner et al. [11] experimental in-cylinder pressure data and endoscopic chemiluminescence images were used to evaluate the effects of different side and centrally located injector nozzle designs on hydrogen engine performance and emissions. At low-load conditions, the side injectors showed higher thermal efficiency than the central ones. Kaiser and White [15] used PIV and Planar Laser Induced Fluorescence (PLIF) to study hydrogen injection and mixing in an optical DI engine with a side 6-hole injector for different injection strategies after IVC. The results demonstrated that the injection event changed profoundly the in-cylinder flow field. Rich and lean regions were separated by a mixing region with sharp instantaneous gradients and high standard deviation spatially coinciding with the local turbulence in the measured flow field. The PLIF work was expanded by Slazar and Kaiser [16] with different injector locations and nozzle configurations in combination with various injection timings.

Scarcelli et al. [12] used the same PLIF technique along with RANS modelling to understand the in-cylinder hydrogen distribution for a centrally mounted injector with different single-hole jetting orientations and at different injection timings after IVC at low-load engine conditions. For early injection, the flow field proved to have the main influence on the engine's efficiency. An injection direction which exploited the air tumble motion was found preferable for optimised mixture stratification around the spark-plug. For late injection, the flow field did not have a significant influence on the mixture formation process. In a later publication, Scarcelli et

Page 2 of 26 
al. [17] used RANS and PLIF to study in-cylinder hydrogen injection with various injection strategies, injection pressures, and injector orientations. Realizable $k$ - $\varepsilon$ turbulence modelling was enabled. The simulation of a multi-hole nozzle showed the least accurate results in terms of both initial jet penetration and final fuel distribution. The authors' hypothesis was that the jet-to-jet interaction occurring in the under-expanded region was not captured with the used resolution. Increasing grid resolution and performing Large Eddy Simulation (LES) was suggested as the way forward to improve the accuracy of numerical predictions. The features of subsonic and sonic under-expanded hydrogen injection were studied by Owston et al. [13]. These authors performed RANS simulations of the effect of exit-to-chamber pressure ratio using 'standard' $k-\varepsilon$ modelling. They highlighted that the higher the exit-tochamber pressure ratio, the higher the grid resolution required. Coarser resolution underpredicted mixing and increasing exitto-chamber pressure ratios resulted in decreasing penetration and increasing spreading rates for the sonic hydrogen jets. Increasing the ratio affected the expansion region, i.e. the barrel length and shock structure. The authors specifically concluded that the resolution that they employed was not adequate to resolve these details. Under-expanded jets have been studied for air and gaseous fuels (primarily natural gas), experimentally [31-35] and by LES [36-39]. In a recent publication on under-expanded jets, Scarcelli et al. [40] validated RANS predictions of a sonic argon jet, injected at a flow rate corresponding to $100 \mathrm{bar}$ nominal injection pressure into atmospheric environment, against experimental data obtained by means of X-ray radiography. The predictions of argon mass distribution along the jet axis were in agreement with the X-ray measurements, particularly far from the nozzle exit and close to the mixing region. Applying higher than first order discretization for the momentum equation in combination with a lower time step than about $0.1 \mu$ s and finer grid resolution than $0.1 \mathrm{~mm}$ were suggested in order to reduce the discrepancy between RANS and experiments [40]. Hydrogen under-expanded jets pose several issues with their study due to their speed in excess of $1200 \mathrm{~m} / \mathrm{s}$, hence previous computational and experimental work on hydrogen is not as common. Drozda and Oefelein [41] applied large eddy simulation (LES) to investigate high pressure hydrogen injection for DI hydrogen engine applications. The LES results were compared against experimental shadowgraph images and showed good qualitative and quantitative agreement [41].

\section{Present Contribution}

Previous work by other authors has discussed various aspects of hydrogen injection for DI engines. Numerical simulations have demonstrated their potential to predict features of the incylinder injection, flow interactions and mixture formation. However, they also highlighted the requirement for high spatial resolution in order to capture sonic flow effects, as well as the need for more sophisticated modelling based on LES. Previous work by a co-author of the current paper focused on spark-ignition and controlled auto-ignition studies of hydrogen combustion in an optical engine. The engine used a side 6-hole injector with a stepped nozzle, typical of gasoline DI systems. The combustion imaging results indicated distorted flame shapes whose origin was thought to be related to the momentum exchange between hydrogen jetting and incylinder air-flow [4, 14, 42]. As far as boosted hydrogen engines are concerned, most of the published work has been done with PFI. The aim of the current wok was to computationally study the effect of in-cylinder DI injection and mixing on the flow field and fuel concentration at ignition timing using a DI combustion system at boosted operation. High spatial and temporal resolution was applied in order to perform direct comparison between RANS and LES. The specific objectives of the work are summarised below:

- RANS of hydrogen injection from a single orifice injector in a quiescent environment to compare against previous RANS work with the same conditions.

- RANS and LES of hydrogen injection in a quiescent environment using a single orifice straight nozzle and a stepped injector-hole geometry in order to study the effects of nozzle design on hydrogen's jetting characteristics.

- Study of the shock behaviour of under-expanded hydrogen jets for different ratios of injection/ambient pressure.

- RANS and LES of in-cylinder flow, hydrogen injection and mixing with a 6-hole side injector up to the end of compression.

The results are discussed in conjunction with effects of injection pressure, injection duration and time from the start of injection.

\section{COMPUTATIONAL METHODOLOGY}

Various codes were initially considered in this investigation. KIVA, OpenFOAM and STAR-CCM+ were all examined and were compared with existing results from the same engine obtained by STAR-CD simulations, as well as PIV and Laser Doppler Velocimetry (LDV) (published earlier in [43]). Finally, it was decided to use STAR-CCM+ for the objectives of the current work, although it is expected that benchmark calculations with all codes will be discussed in a future publication. RANS work was performed with the 'standard' high-Reynolds number $k-\varepsilon$ model [44], whilst for LES the standard Smagorinsky [45] model was employed.

\section{Nozzle-Hole Geometry and Grid}

In order to validate the capabilities of the computational frame work to capture the important characteristics of the underexpanded sonic hydrogen jets a RANS test case was prepared based on computational data from literature [13]. A cylindrical computational grid with $10 \mathrm{~cm}$ diameter and $16 \mathrm{~cm}$ length containing $\sim 4.0$ million hexahedral cells was created. The nozzle was a simple orifice with a diameter $D$ of $1 \mathrm{~mm}$. A very refined area with $D / 20$ spacing resolution in both axial and radial directions was created very close to the nozzle exit

Page 3 of 26 
in order to capture the expansion shocks structure. This refined area had a size of $10 D$ in the axial direction and $5 D$ in the radial. Following that refined area, the grid's spacing was gradually increased to a cell size of $\sim 0.5 \mathrm{~mm}$ uniformly distributed throughout the rest of the computational domain. Stagnation inlet was used as boundary condition at the nozzle exit, no-slip wall condition was used at the side wall, and pressure boundary was applied at the bottom boundary. Nozzle exit conditions for pressure, velocity and temperature were calculated to be $21.47 \mathrm{bar}, 1363 \mathrm{~m} / \mathrm{s}$, and $320 \mathrm{~K}$, respectively. Initial conditions inside the domain were set to $330 \mathrm{~K}$ in temperature, $10 \mathrm{~kg} / \mathrm{m}^{3}$ in density, and quiescent in nature.

Following this test case, the work focused on simulations of hydrogen jest from straight and stepped nozzle holes. Stepped injector geometries are typical for multi-hole injectors for gasoline direction injection engines. Such a type of injector has been used by at University College London for optical studies of hydrogen combustion in a single-cylinder DI research engine [14]. The geometry of the holes was characterized by creating castings of the injector holes, using techniques described in [46] as shown in Figure 1, and the diameter of the outer and inner hole was measured to be 0.2 $\mathrm{mm}$ and $0.4 \mathrm{~mm}$, respectively. The depth of the injector hole was measured to be $\sim 0.66 \mathrm{~mm}$, divided equally between the narrow and wide nozzle-hole sections. The geometry was modeled by integrating it to a reservoir tank and a fixed volume wall-bounded chamber (using a converging nozzle), as shown in Figure 2. The total pressure and temperature of the fuel reservoir were $100 \mathrm{bar}$ and $320 \mathrm{~K}$, respectively. The temperature for the chamber was $358 \mathrm{~K}$; in order to investigate the effect of pressure ratio on under-expanded hydrogen jets, two different chamber pressures of 1.5 bar and 6 bar were considered. The chamber was $50 \mathrm{~mm}$ in height and $40 \mathrm{~mm}$ in diameter.

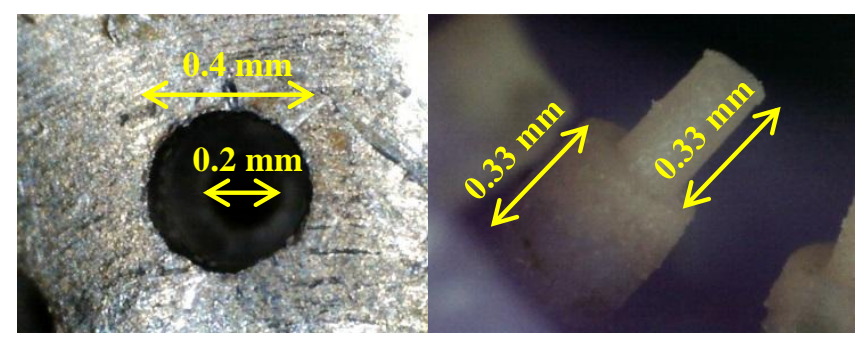

Figure 1. Microscopic images of the stepped injector hole (left) and its casting (right).

In order to capture the structure of the jet inside the stepped injector and very close to the injector exit, special grid refinements were used. A global maximum cell size of $0.8 \mathrm{~mm}$ was selected for the main chamber. The cell size close to the walls was adjusted to be between $0.3 \mathrm{~mm}$ to $0.5 \mathrm{~mm}$. Two special refinement areas were designed in order to resolve the volume of the stepped injector and areas close to the converging nozzle inlet and also nozzle expansion and exit regions. For the finest area, the cell size was $0.02 \mathrm{~mm}$, equally

Page 4 of 26 distributed in all directions. For the refined area further downstream of the nozzle exit, a uniform cell size of $0.1 \mathrm{~mm}$ was applied. In total $\sim 7$ million hexahedral cells resolved the computational domain; see Figure 2. An identical approach was used to create a polyhedral grid as well for the stepped injector, as also shown in Figure 2; this was $\sim 5$ million cells in size. Finally a hexahedral grid was prepared for a nozzle of fixed diameter $0.2 \mathrm{~mm}$, equivalent to the dimensions of the stepped injector, hence $\sim 7$ million cells in size. Both RANS and LES studies were conducted on those grids.

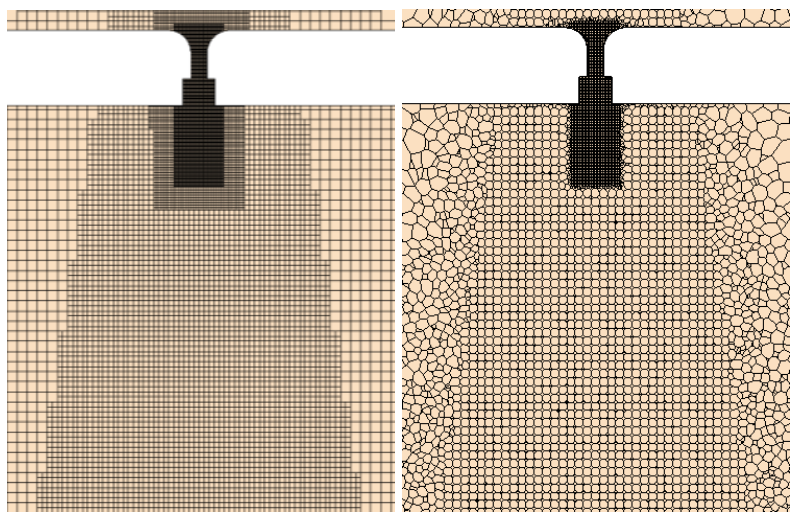

Figure 2. Zoomed view of the middle section plane of the computational grids used for the stepped injector simulations, hexahedral (left), polyhedral (right).

All test cases have been numbered and summarised in Table 1.

\section{Table 1. Test cases of hydrogen injection into quiescent environment.}

\begin{tabular}{|l|c|c|c|c|c|c|}
\hline Test Case & $\begin{array}{c}\boldsymbol{P}_{\boldsymbol{0}} \\
{[\mathbf{b a r}]}\end{array}$ & $\begin{array}{c}\boldsymbol{T}_{\boldsymbol{0}} \\
{[\mathbf{K}]}\end{array}$ & $\begin{array}{c}\boldsymbol{P}_{\boldsymbol{a}} \\
{[\mathbf{b a r}]}\end{array}$ & $\begin{array}{c}\boldsymbol{T}_{\boldsymbol{a}} \\
{[\mathbf{K}]}\end{array}$ & Grid & Method \\
\hline $\begin{array}{l}\text { 1. Validation } \\
(D=1 \mathrm{~mm})\end{array}$ & 40.66 & 384 & 9.5 & 330 & Hexa & RANS \\
\hline $\begin{array}{l}\text { 2. Stepped } \\
(D=0.2 \rightarrow 0.4 \mathrm{~mm})\end{array}$ & 100 & 320 & 1.5 & 358 & Hexa & RANS \\
\hline $\begin{array}{l}\text { 3. Stepped } \\
(D=0.2 \rightarrow 0.4 \mathrm{~mm})\end{array}$ & 100 & 320 & 1.5 & 358 & Poly & RANS \\
\hline $\begin{array}{l}\text { 4. Stepped } \\
(D=0.2 \rightarrow 0.4 \mathrm{~mm})\end{array}$ & 100 & 320 & 1.5 & 358 & Hexa & LES \\
\hline $\begin{array}{l}\text { 5. Stepped } \\
(D=0.2 \rightarrow 0.4 \mathrm{~mm})\end{array}$ & 100 & 320 & 6 & 358 & Hexa & RANS \\
\hline $\begin{array}{l}\text { 6. Stepped } \\
(D=0.2 \rightarrow 0.4 \mathrm{~mm})\end{array}$ & 100 & 320 & 6 & 358 & Hexa & LES \\
\hline $\begin{array}{l}\text { 7. Straight } \\
(D=0.2 \mathrm{~mm})\end{array}$ & 100 & 320 & 1.5 & 358 & Hexa & RANS \\
\hline
\end{tabular}




\section{Engine Geometry and Grid}

The engine geometry in which the present computational work was performed corresponds to one cylinder of a 4-cylinder 2liter engine. The structure and characteristics of the in-cylinder flow for this engine has been investigated previously by means of PIV, LDV and RANS [43] using normally aspirated conditions. Table 2 summarizes important geometrical and operational characteristics of the engine (where ${ }^{\circ} \mathrm{CA}$ corresponds to degrees Crank Angle).

Creating structured hexahedral grids for complex geometries, such as advanced IC engines with complex pent-roof and ports shapes, is very time consuming and in some cases it can be impossible to capture all details of the combustion chamber. For the current work, a methodology had to be developed to create new faithful moving grids that could be compatible with the current capabilities of STAR-CCM+ (and other codes like OpenFOAM). Specifically, a dynamic grid methodology was employed that could account piston and valve motion throughout the cycle.

Table 2. Engine Geometry and Operating Conditions.

\begin{tabular}{|l|l|}
\hline Engine Head & 4-valve Pent-roof \\
\hline Piston Shape & Flat \\
\hline Bore $[\mathrm{mm}] \times$ Stroke $[\mathrm{mm}]$ & $82.5 \times 88.9$ \\
\hline Connecting Rod $[\mathrm{mm}]$ & 165.2 \\
\hline Injection System & DI Multi-Hole \\
\hline Compression Ratio & $9.8: 1$ \\
\hline Engine Speed $[\mathrm{RPM}]$ & 1500 \\
\hline Intake Pressure $[\mathrm{bar}]$ & 1.5 \\
\hline Valve Timings $\left[{ }^{\circ} \mathrm{CA}\right.$ ATDC] & IVO: 695, IVC: 235 \\
\hline Injection Timing $\left[{ }^{\circ} \mathrm{CA}\right.$ ATDC] & 240 \\
\hline
\end{tabular}

Piston and valve velocity profiles with $0.1^{\circ} \mathrm{CA}$ temporal resolution were given to the code as a tabular input file. Typically, for every $10-15 \mathrm{~mm}$ of the piston's stroke motion, the computational domain was replaced by a new grid in order to avoid potential numerical issues from highly compressed or stretched computational cells. Furthermore, close to opening or closure of the valves, where the piston's stroke motion is slow and the valve's opening/closing gap is small with the valve moving rapidly at the same time, the domain was replaced by a new grid more frequently (to avoid further issues of local cell deformation, high skewness, etc.). The computational grid of the engine was a hybrid grid: hexahedral cells were used to resolve the piston's swap volume; polyhedral cells were employed for the pent-roof and intake ports. In total a sum of 24 hybrid grids were used to solve the full intake and compression strokes. For the compression stroke after IVC the intake ports were eliminated from the computational domain in order to save computational cost. The maximum cell size close to the walls was chosen to be Page 5 of 26
0.4-0.7 $\mathrm{mm}$ and the maximum cell size inside the computational domain was set to be $0.8 \mathrm{~mm}$. The computational grid of the swept volume varied from $\sim 3.0$ million hexahedral cells at the end of the intake stroke to $\sim 500,000$ cells at the end of the compression stroke; this was used for airflow simulations. For the in-cylinder hydrogen injection simulations, greater resolution was required to capture the physical process involved, hence a grid of about 6 million cells was prepared, with about 2.5 million cells in the pent-roof. The minimum cell size of this grid was $\sim 0.04 \mathrm{~mm}$ at the injection nozzle location.

RANS was used to simulate the intake and compression strokes of the engine, including the process of hydrogen injection. LES was only used to predict the hydrogen-air mixture formation after IVC by initialization based on the RANS calculated flow field at IVC. Identical hexahedral grids were used in the swap volume for both RANS and LES grids for direct comparison. At the end of compression the pent-roof volume was resolved by trimmed hexahedral cells. Second order discretization schemes were used for both RANS and LES. A time step of $0.1^{\circ} \mathrm{CA}$ was selected for RANS during the intake and compression strokes under non-fuelled conditions. During the hydrogen injection process, a time step of $0.02^{\circ} \mathrm{CA}$ was used for both RANS and LES.

\section{In-Cylinder Hydrogen Injection}

A multi-hole injector with stepped nozzle geometry was used for the in-cylinder simulations. The injector had a 6-hole arrangement that consisted of two groups of 3 asymmetric holes and was mounted $45^{\circ}$ incline on the intake side between the intake valves as shown in Figure 3. According to previous experimental work with this injector and hydrogen fuelling [4, 14] it was decided to adopt the injector orientation with the two sets of plumes pointing upwards towards the pent-roof. The orientation of each injector hole was set based on angles measured from gasoline spray images previously acquired with this injector [47].

Two injection durations of $6 \mathrm{~ms}\left(54^{\circ} \mathrm{CA}\right)$ and $8 \mathrm{~ms}\left(72^{\circ} \mathrm{CA}\right)$ were employed, as well as 70 bar and 100 bar injection pressure with $320 \mathrm{~K}$ total temperature. The respective global equivalence ratios are shown in Table 3. For LES, the study was done with both injection durations but for 100 bar injection pressure only.

Table 3. Global In-Cylinder Equivalence Ratio.

\begin{tabular}{|c|c|c|}
\hline \multirow{2}{*}{ Injection Pressure } & \multicolumn{2}{|c|}{ Duration } \\
\cline { 2 - 3 } & $6 \mathrm{~ms}$ & $8 \mathrm{~ms}$ \\
\hline $70 \mathrm{bar}$ & $\phi=0.23$ & $\phi=0.30$ \\
\hline $100 \mathrm{bar}$ & $\phi=0.32$ & $\phi=0.42$ \\
\hline
\end{tabular}




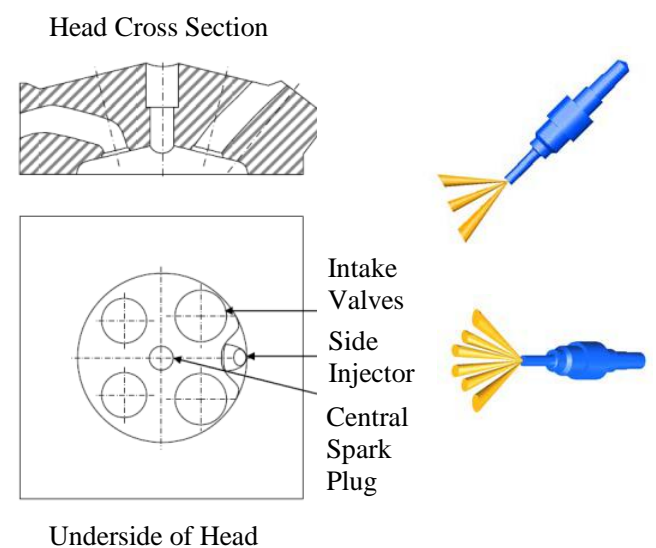

Figure 3.Orientation of the multi-hole injector with nominal injection jet pattern $[14,47]$.

\section{RESULTS AND DISCUSSION}

\section{Under-Expanded Hydrogen Jets}

Before introducing the results, some basics of under-expanded jet behavior are explained here for completeness.

The three major flow categories of a gas flow jet issued from a circular nozzle are subsonic, moderately under-expanded jet, and highly under-expanded; see Figure 4 for under-expanded cases [31]. When the critical pressure ratio is reached, which is 1.889 for hydrogen, a very weak normal shock is expected to form at the exit. Increasing this pressure ratio has significant effects on the shock. Above a particular ratio, a pattern of diamond-shape shocks composed of crossing oblique shock waves is established in the jet core. At very high pressure ratios the structure of the first shock 'cell' start to change; along the centerline, the pressure becomes so low relative to ambient that the recompression in the remainder of the cell reaches the limiting value for conical shocks, and the required compression occurs through a normal shock known as Mach disk. A sonic jet is categorized as highly underexpanded if the Mach disk exists in its expansion region. By further increase in pressure ratio, the Mach disk increases in height and diameter. Immediately downstream of the disk, the flow is subsonic. A slip line divides the surrounding subsonic and sonic core regions of the oblique shock. For moderately high pressure ratios the subsonic core region is quickly accelerated and becomes supersonic once again near the beginning of the second shock cell. In this case the second cell behaves like the first cell and even holds a similar normal shock. For very high pressure ratios, the structure downstream of the first cell is affected by the very strong normal shock in the first cell and the flow decays through a formation of oblique shocks. A mixing region surrounds the core as usual, but its radial diffusion is small which results in an extremely long highly under-expanded core. Far downstream, a typical subsonic decay occurs.
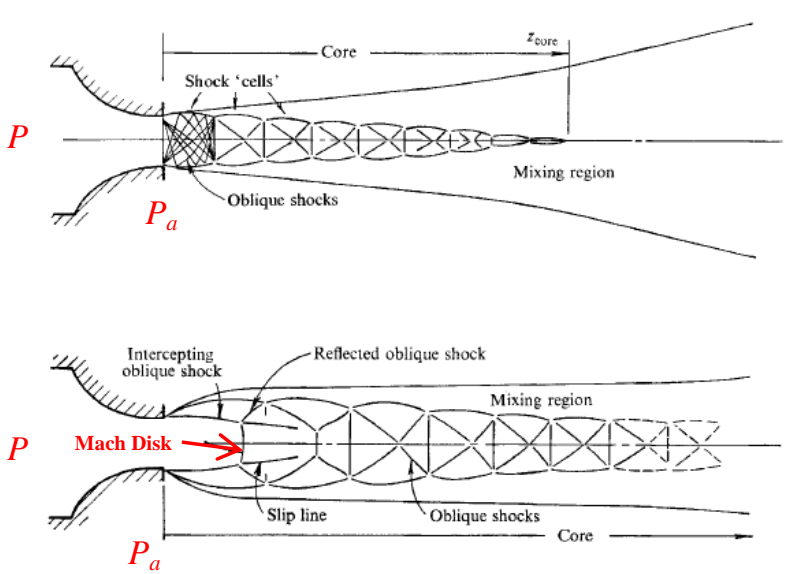

Figure 4. Schematic of moderately under-expanded (top) and highly under-expanded gaseous jets (bottom) [31].

\section{Reference Test Case}

As already mentioned, initially a RANS test case was chosen from the literature [13] in order to set a baseline comparison between the current methodology and previously published work by other authors; see Test Case 1 in Table 1. Figure 5 compares the jet penetration of this case as calculated by the current authors work with what reproduced from [13]. It is seen that there is about $\sim 15 \%$ higher penetration with the current methodology. In turn, Figure 6 illustrates some important flow characteristics of this case close to the nozzle exit at $100 \mu \mathrm{s}$ ASOI; the quantities shown have been normalized by their value at the nozzle exit. It is clear that a higher maximum value of $M a$, about 2.5, was captured in comparison to the value of $\sim 1.7$ in [13]. The oscillations of the Mach graph in Figure 6 also show that the current simulation captured 6 shocks over a length of $10 \mathrm{~mm}$ from the nozzle exit $(10 D)$; the original publication captured only one shock. This detail in resolving the shocks is also illustrated by the computational prediction of the pressure field shown in Figure 7 in grey scale; no legend is given here as the limits of the scale were simply adjusted to make the shocks as clearly visible as possible. With reference to Figure 4, the phenomena of Figure 7 can be categorized as those of a moderately underexpanded jet (no Mach disk present; pattern of first cell followed by diamond shape shocks that cover the jet core). The detailed observations are due to the much finer grid resolution used over the first $10 \mathrm{~mm}(10 D)$ distance from the nozzle here than that used in [13]. The larger penetration is an effect of capturing those shock details and higher velocity magnitude close to the nozzle exit.

It should be noted that due to the negative Joule-Thomson coefficient of hydrogen (unlike most gases hydrogen warms up during a sudden expansion process), temperature profile characteristics very close to the nozzle exit cannot be captured by using an ideal gas equation of state. The present work used an ideal gas equation; therefore, the temperature profile in Figure 6 very close to the nozzle exit may not be 
quantitatively representative of the real process. However, various real gas equations are currently under investigation by the current authors (e.g. see equations in [48-49]).

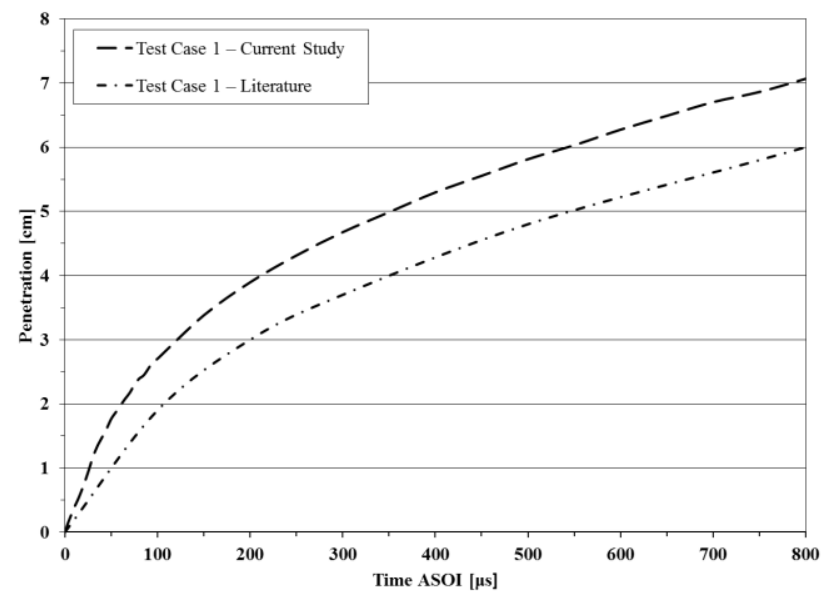

Figure 5. Hydrogen penetration; Test Case 1.

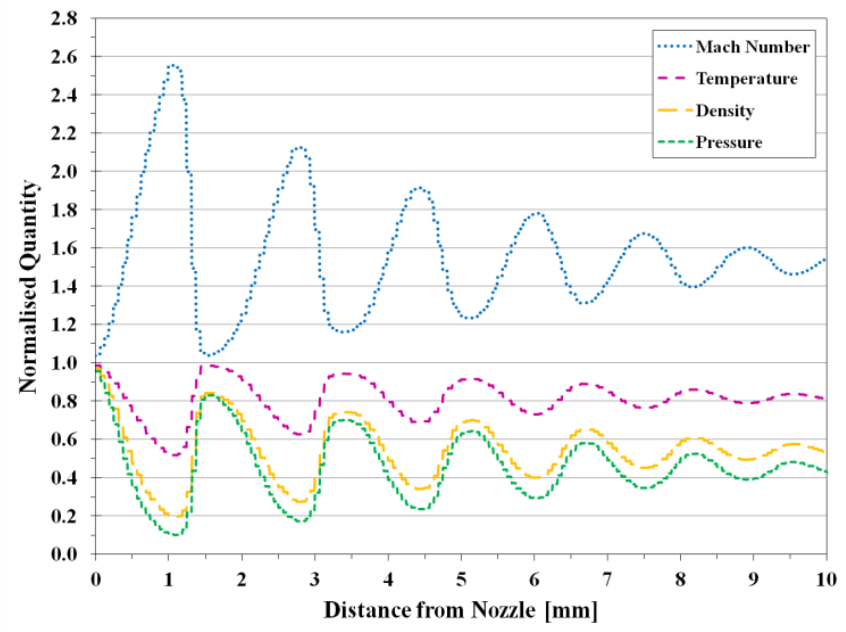

Figure 6. Characteristics of hydrogen jet close to the nozzle exit; Test Case 1 (100 $\mu \mathrm{s}$ ASOI).

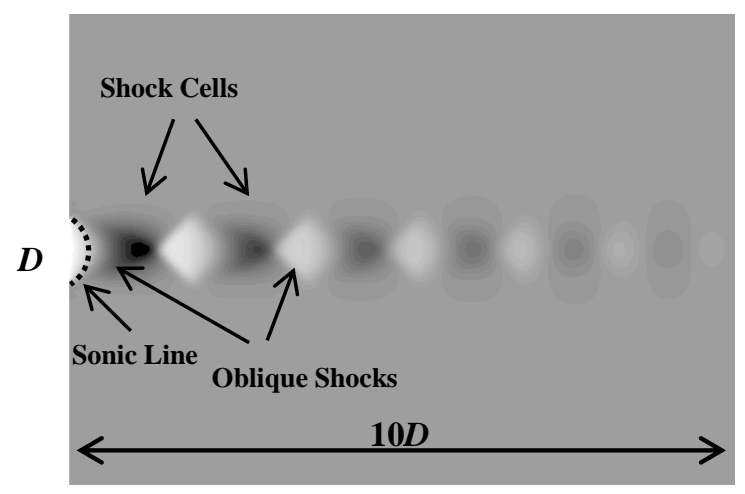

Figure 7. RANS prediction of shock waves structure close to the nozzle exit; Test Case 1 (100 $\mu \mathrm{s}$ ASOI).

\section{Straight and Stepped Nozzles}

Figure 8 shows the development of transient hydrogen jets for Test Cases 2-7 of Table 1 (contours based on mole fraction of hydrogen). Then Figures 9 and 10 show details of the shock region close to the nozzle exit. Quantitative details of those are discussed below but it is immediately clear that the straight nozzle (Test case 7) led to lower penetration than the stepped one (Test case 2) from early on, as well as greater radial width, particularly for 25 and $50 \mu$ s ASOI. Furthermore, the LES results of Test Case 4 illustrate the effect that the shock has on the radial expansion of the hydrogen jet close to the nozzle in comparison to RANS (Test Case 2). The polyhedral grid of Test Case 3 shows slightly lower penetration and less shock features that the hexahedral of Test Case 2.

Figure 9 compares the RANS and LES ability to capture shock structures close to the nozzle exit for the four different cases of the stepped injector (Test Cases 2, 4-6). A grey scale legend is used in Figure 9(b) and 9(d) to offer better visualization of the shock structure (as done earlier in Figure 7 too). LES clearly predicted a more detailed shock behavior than RANS. Increasing the ambient pressure from 1.5 bar to 6 bar caused a lower flow acceleration after the Mach disk. For all test cases the sonic condition occurred at the exit of the 0.2 $\mathrm{mm}$ inner hole of the stepped design. Figure 10 shows the Mach disk for the straight nozzle (Test Case 7). The height of the Mach disk $\left(H_{\text {disk }}\right)$ can be calculated using the empirical relation in Equation (1). The value of the constant $C$ has been suggested to be 0.67 for pressure ratios higher than 10 and 0.55 for smaller pressure ratios $[35,39]$. For the pressure ratio of $\sim 67$ of Test Case 7 in Figure 10, using $C=0.67$, the height of the Mach disk $H_{\text {disk }}$ is calculated to be $\sim 5.5$ times greater than the nozzle diameter $(D=0.2 \mathrm{~mm})$. This is the same to the height obtained from the computational results of Figure 10.

$$
H_{\text {disk }} / D=C\left(P_{0} / P_{a}\right)^{1 / 2}
$$

The width of the Mach disk ( $W_{\text {disk }}$ ) can also be estimated using a similar empirical relation to Equation (1). However, the respective constant $C_{w}$ is highly dependent on the pressure ratio. For nitrogen, the value of $C_{w}$ increases for higher pressure ratios; for instance, when the pressure ratio increased from 4 to $8, C_{w}$ was calculated to vary from 0.15 to 0.7 in [39]. Assuming hydrogen as an ideal gas and with similar Mach disk characteristics to nitrogen, Equation (1) may be used to estimate the width of the Mach disk $W_{\text {disk }}$ for under-expanded hydrogen jets. Although there are no data available for $C_{w}$ for hydrogen jets under extreme pressure ratios, for the pressure ratio of $\sim 67$ in Figure 10, any value of $C_{w}$ greater than 0.12 would result in a wider disk than the nozzle exit, applying Equation (1). As it can be seen in Figure 10, the Mach disk is 4 times wider than the inner nozzle diameter of $0.2 \mathrm{~mm}$, therefore, based on Equation (1) and for a pressure ratio of $\sim 67$, the coefficient $C_{w}$ would have a value of $\sim 0.49$ for hydrogen. This is in qualitative agreement with the results of the under-expanded argon jet of [40]. 

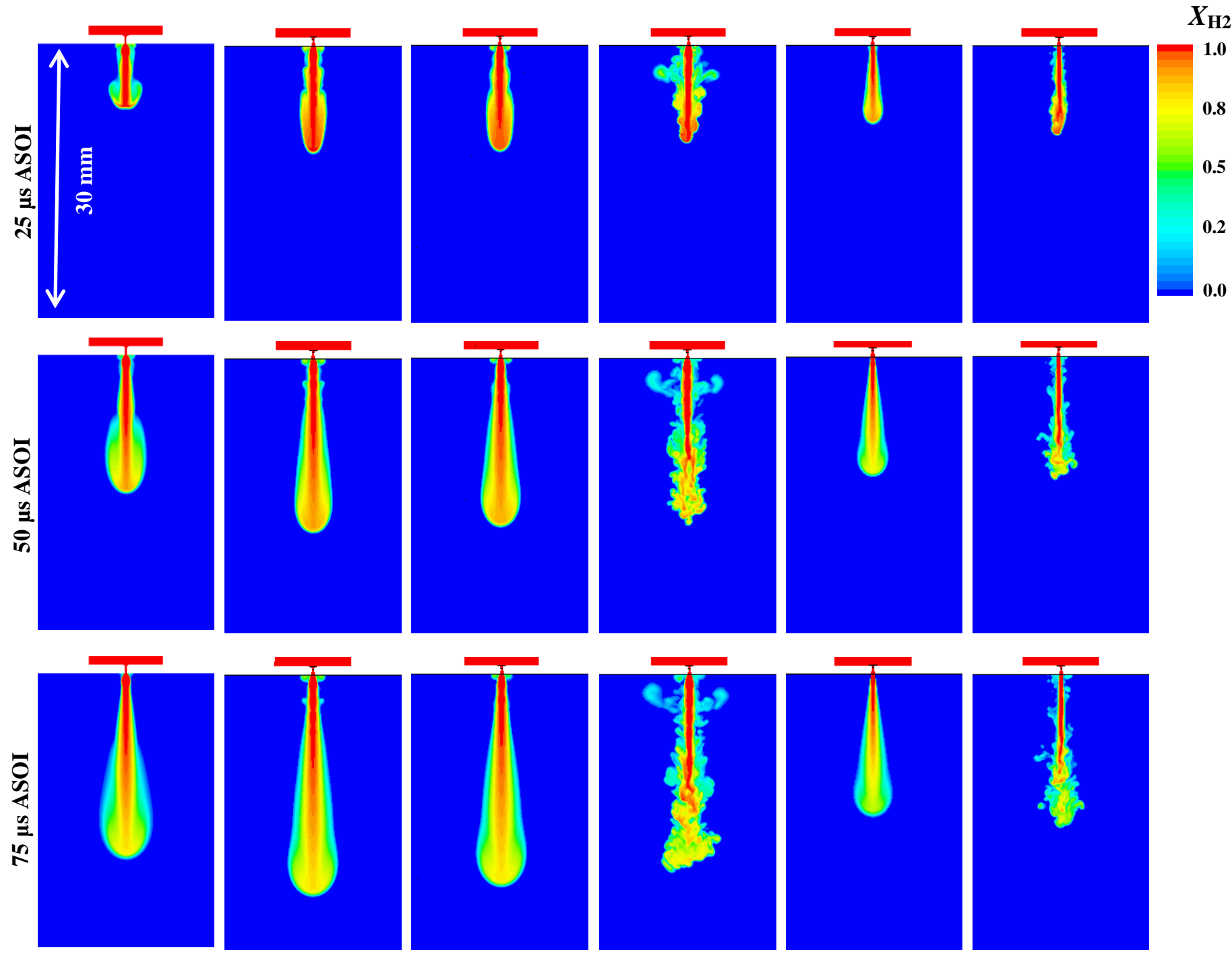

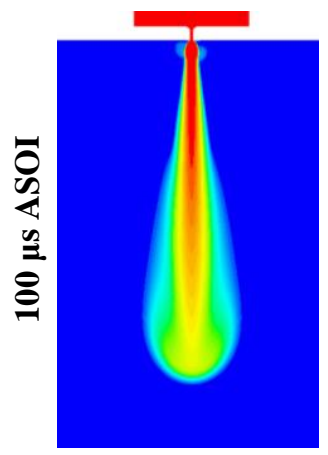

(a)

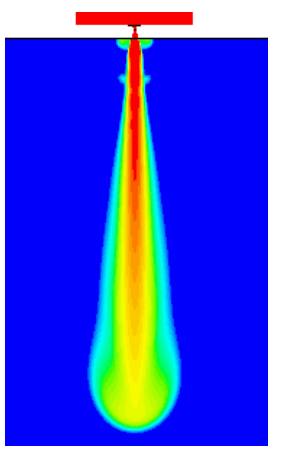

(b)

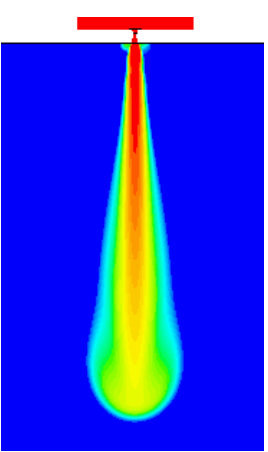

(c)

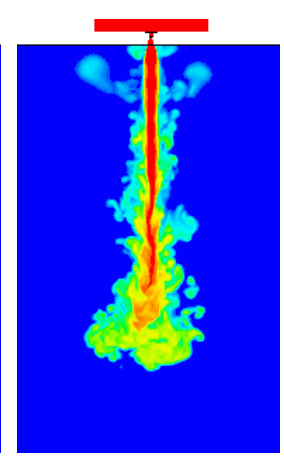

(d)

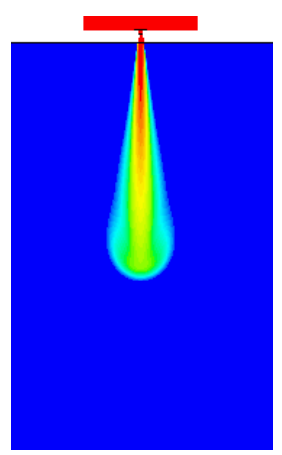

(e)

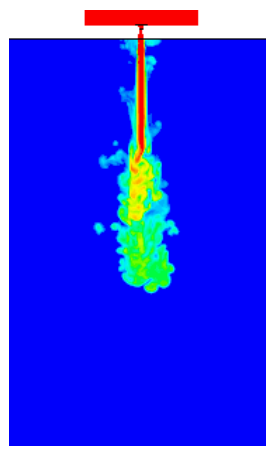

(f)

Figure 8. RANS and LES of hydrogen injection using straight and stepped injectors: (a) Test Case 7, (b) Test Case 2, (c) Test Case 3 (d) Test Case 4, (e) Test Case 5, (f) Test Case 6. 
Figure 9 illustrates that the existence of the step restricted the jet's expansion in the radial direction and reduced the width of the Mach disk to a level smaller than the inner diameter. Comparison between Figures 9 and 10 shows that the stepped design also reduced the height of the disk to almost half of the height that the Mach disk would have in the same pressure ratios with the straight nozzle design. Further computational studies are being performed by the authors of the current paper in order to find a correlation between $C_{w}$ and injection pressure for extreme pressure ratios in both stepped and straight nozzle designs.

Figure 11 compares hydrogen's tip penetration for Test Cases 2-7 (0.1\% hydrogen mole fraction was as tip threshold). It can be observed that the stepped nozzle of Test Case 2 leads to higher penetration than that of the straight nozzle of Test Case 7. The Mach number profile very close to the nozzle exit is shown in Figure 12 at $100 \mu$ s ASOI. It is clear that the straight hole injector leads to a large initial peak, as also illustrated by the strong Mach disk of Figure 10; then the speed decays to subsonic values. In contrast, the stepped injector demonstrates several peaks in Figure 12 as a result of several shocks, and supersonic conditions throughout. Therefore, the lower hydrogen tip penetration of the straight nozzle Test case 7) can be a result of the sudden drop in velocity magnitude and the occurrence of subsonic/sonic conditions further downstream.

It is also clear that the LES calculation of Test Case 4 predicted shorter penetration than the same case simulated by RANS (Test Case 2), especially from $50 \mu$ ASOI. This case corresponded to a pressure ratio in excess of 65 . In contrast when comparing Test Case 5 (RANS) and Test Case 6 (LES) with a pressure ratio of about 17 , the penetration of LES is larger than that of RANS. This difference in penetration behavior between Test Cases $2 \& 4$ and $5 \& 6$ is believed to stem from shock phenomena related to pressure ratio. For the lower pressure ratio, the Mach number of RANS after the first shocks decays steadily to subsonic values, whilst for LES it remains steadily supersonic for the first $40 D(8 \mathrm{~mm})$. For the larger pressure ratio, RANS predicts the same number of shocks to that of LES; however, the effect weakens after $\sim 30 D$ $(6 \mathrm{~mm})$. The lower penetration by LES on this occasion is primarily a result of the increased radial expansion of the jet close to the nozzle as shown in Figure 8 (in comparison to RANS) and also highlighted by the close-up LES images of Test Cases 4 and 6 in Figure 13. The lower pressure ratio leads to weaker shocks and smaller jet tip vortices, hence a weaker effect on the jet's expansion in radial direction. (a)

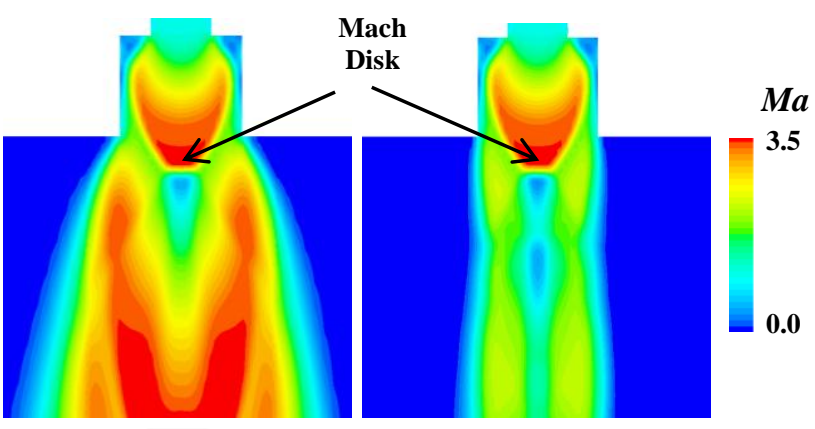

(b)

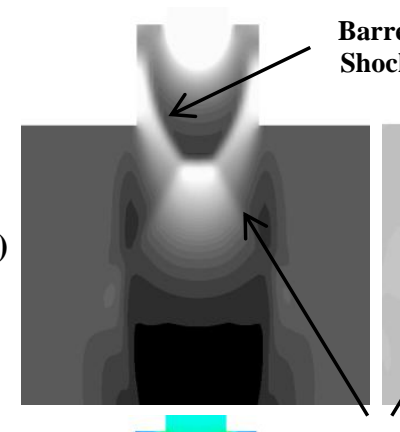

Barrel

Shock

(c)

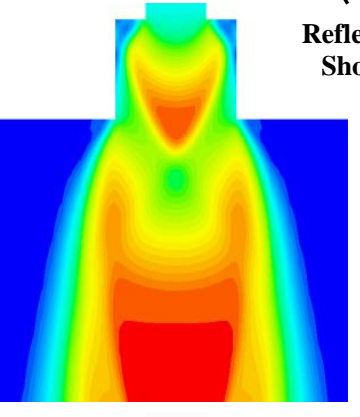

Reflected

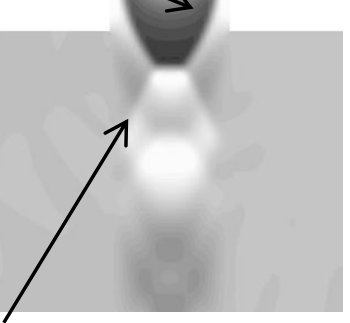

(d)
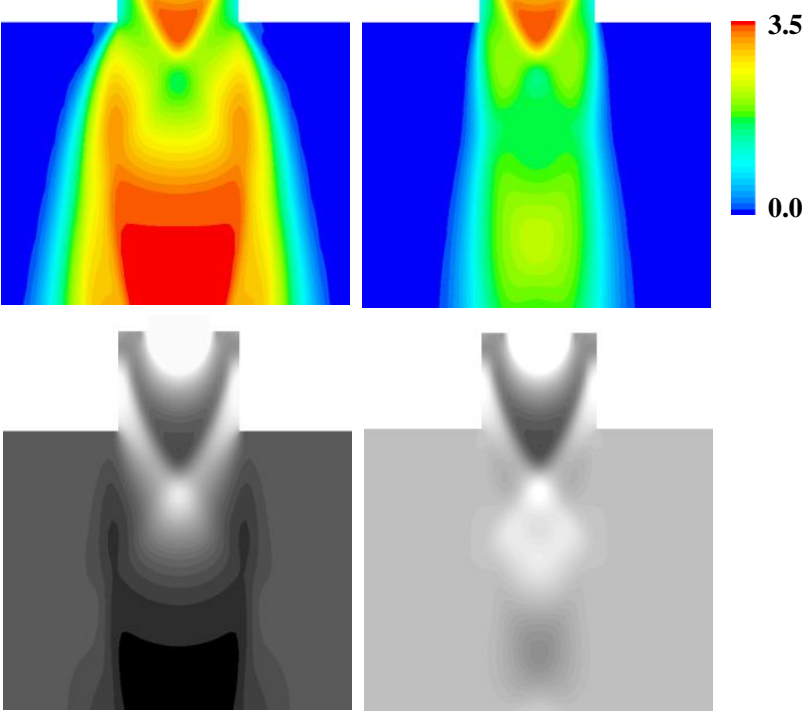

$P_{a}=1.5 \mathrm{bar}$

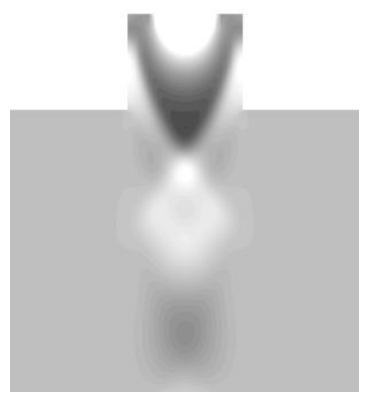

$P_{a}=6$ bar

Figure 9. (a) \& (b) LES, Left: Test Case 4, Right: Test Case 6; (c) \& (d) RANS, Left: Test Case 2, Right: Test Case 5. 


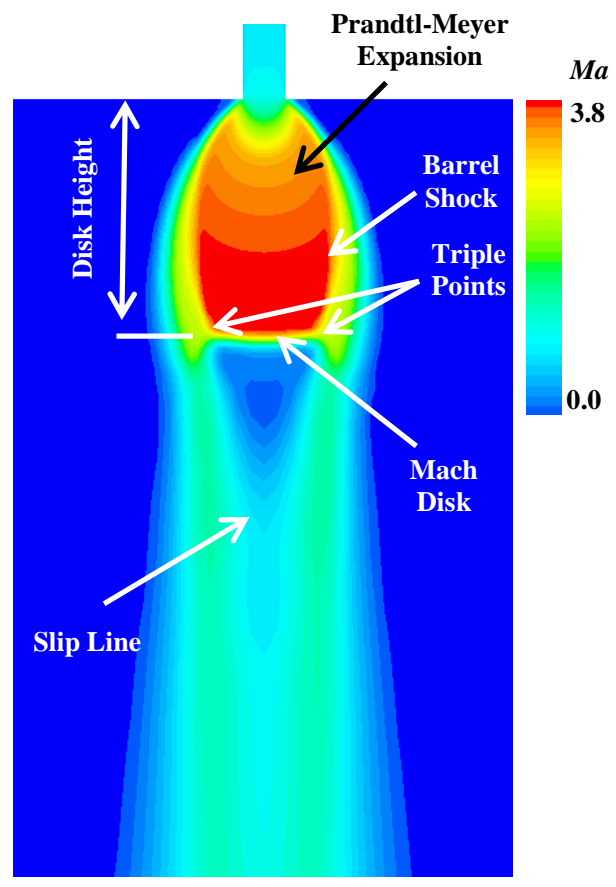

Figure 10. Shock Structure close to the nozzle exit for the straight nozzle; Test Case 7.

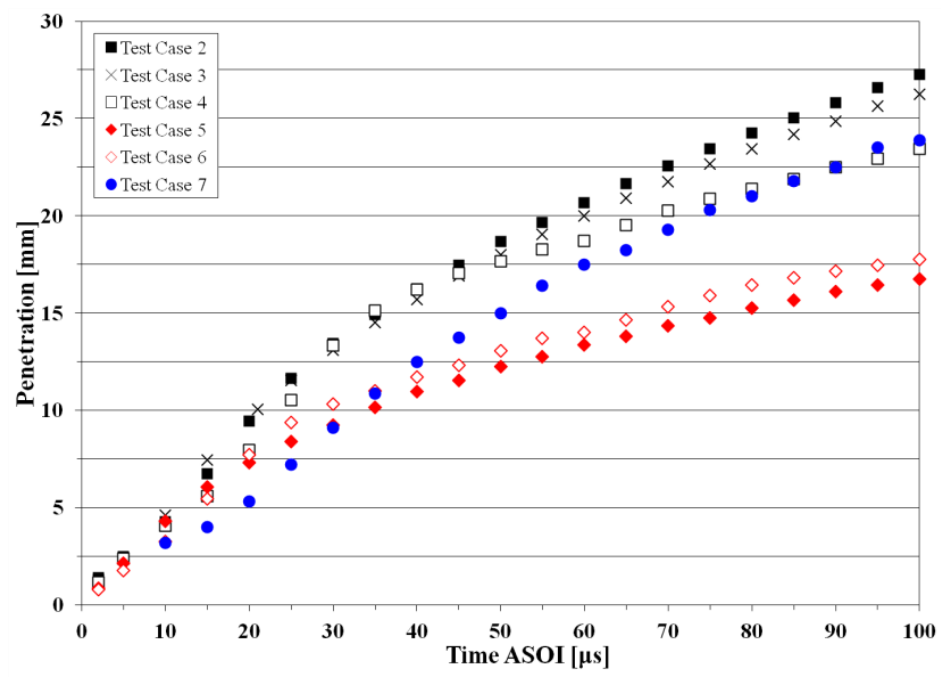

Figure 11. Hydrogen jet penetration; Test Cases 2-7.

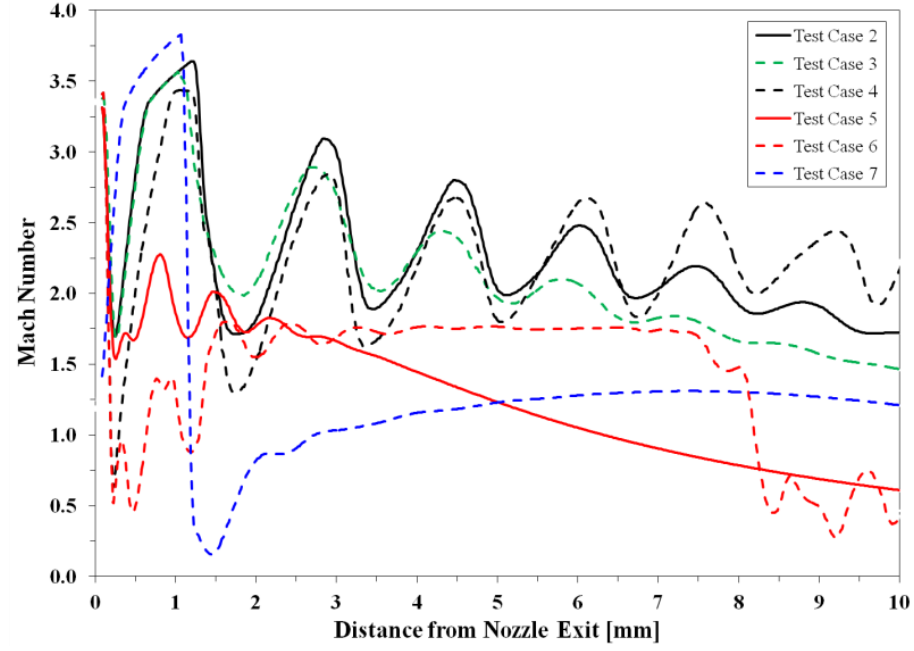

Figure 12. Mach number on the centreline close to the nozzle exit; Test Cases 2-7 (100 $\mu \mathrm{s}$ ASOI).

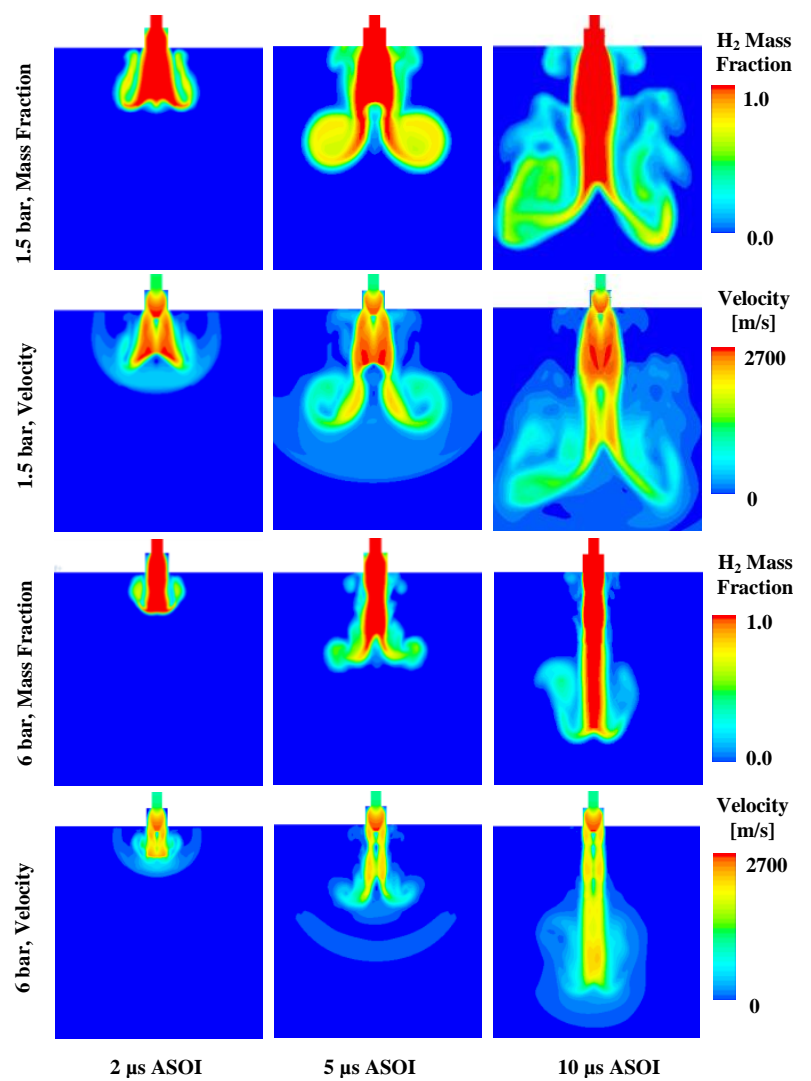

Figure 13. Effect of pressure ratio on shock structure and hydrogen penetration close to the nozzle; Test Cases 4, 6. 


\section{Hydrogen Mixture Formation in Engine}

\section{RANS Modelling}

Figure 14 compares RANS predictions of hydrogen-air mixing on the central tumble plane for two test cases with injection pressure 70 and 100 bar. Hydrogen is injected at $240^{\circ} \mathrm{CA}$ ATDC (i.e. soon after IVC) for $6 \mathrm{~ms}\left(54^{\circ} \mathrm{CA}\right)$. Due to the orientation of the injector holes the vertical plane does not cut through any hole. In Figure 14 and subsequent similar figures, the range of hydrogen mole fraction has been dynamically varied during the injection to demonstrate more prominently differences between various injection strategies and methods. Figure 15 shows a comparison between the same two test cases on a horizontal plane located $10 \mathrm{~mm}$ below the engine's fire face (intake valves at the top, exhaust valves at the bottom of the circular bore). For both injection pressures the main airfuel mixing process starts after the occurrence of multiple hydrogen jet impingements on the cylinder wall and piston. After the End of the Injection (EOI) very inhomogeneous mixture has been produced with the rich zones located close to the pent-roof and cylinder walls on the exhaust side of the engine. For the 100 bar case the rich area penetrates further towards the middle of the cylinder. The particular injectorhole orientation, jet-wall impingement and the piston's upward motion lead to a circulating tumble motion of the hydrogen cloud. This circulation helps dispersion of the fuel and causes the rich area to move from the exhaust side towards the intake. At $310^{\circ} \mathrm{CA}$ ATDC, i.e. $16^{\circ} \mathrm{CA}$ AEOI, there is a very lean mixture on top of the combustion chamber and for the rest of the compression stroke. For 70 bar injection, hydrogen is seen to occupy most of the combustion chamber by $330^{\circ} \mathrm{CA}$ ATDC, whilst for 100 bar this occurs $\sim 20^{\circ} \mathrm{CA}$ earlier (i.e. at $310^{\circ} \mathrm{CA}$ ATDC). Even that late in the compression the mixture is still not homogenous and rich zones are present in the vicinity of piston and exhaust.

Figure 16 compares the RANS results of the $8 \mathrm{~ms}$ injection duration on both vertical tumble and $10 \mathrm{~mm}$ horizontal planes. For 100 bar injection pressure, at the EOI hydrogen already occupies all the combustion chamber volume, while for 70 bar hydrogen occupies most of the domain about $10-15^{\circ} \mathrm{CA}$ after EOI. As more fuel is injected in $8 \mathrm{~ms}$ in comparison to $6 \mathrm{~ms}$, a thicker rich mixture zone has formed in the vicinity of the piston at the end of the compression stroke. The richest mixture in both test cases is located in the exhaust quenching zone, similarly to the $6 \mathrm{~ms}$ test case. For $6 \mathrm{~ms}$ injection duration, the volume just downstream of the injector becomes almost devoid of hydrogen after EOI. For $8 \mathrm{~ms}$ injection duration with both 70 and 100 bar injection pressure, just after the EOI, the hydrogen cloud has reached the injector vicinity due to the circulating tumble shape motion. For both 70 and 100 bar injection pressure with $6 \mathrm{~ms}$ and $8 \mathrm{~ms}$ injection duration it is observed that the circulating hydrogen cloud passes under the spark plug and hits the wall on the intake side causing a fairly lean mixture zone to be created around the spark plug. However, injector orientation and injection timing are two important factors that can be adjusted in order to ensure the required hydrogen concentration around the spark plug, hence there is scope for further study and optimization.

\section{$\underline{\text { LES Modelling }}$}

Figure 17 compares RANS and LES results during the injection process with 100 bar pressure on the vertical tumble and $10 \mathrm{~mm}$ horizontal plane. Figures 18 and 19 compare RANS and LES predictions of post-injection mixing for $6 \mathrm{~ms}$ and $8 \mathrm{~ms}$ injection durations, respectively. The general 'bulk' shape of the impinging hydrogen jets and fuel cloud are similar between RANS and LES. RANS captures longer evolution for the hydrogen cloud towards the intake side on the central tumble plane but LES predicts a longer penetration on either side of this plane, i.e. under the intake valves, as shown on the horizontal plane. The general locations of the rich mixture zones for both $6 \mathrm{~ms}$ and $8 \mathrm{~ms}$ at the end of the compression stroke are predicted fairly the same by RANS and LES. Figures 20 and 21 compare the respective maps of equivalence ratio at the end of the compression stroke for the two injection pressures and both $6 \mathrm{~ms}$ and $8 \mathrm{~ms}$ injection durations. RANS generally predicts higher concentration of fuel over a larger area close to the engine walls particularly on the exhaust side in comparison to LES. It should be noted that for a fairer comparison between the two turbulence modelling approaches, RANS results should be compared to average results of multi-cycle LES simulations; although the current comparison has still its merits in terms of deviation from an ensemble mean. Multi-cycle LES of hydrogen injection is being performed at the moment by the current authors.

The global equivalence ratio for 70 bar injection pressure for 6 ms duration was 0.23 (Table 3 ). Figure 20 shows that at the end of compression the largest portion of the engine volume has higher equivalence ratio than the global one, whilst some areas are very lean. The global equivalence ratio for $100 \mathrm{bar}$ injection pressure and $6 \mathrm{~ms}$ duration was calculated to be 0.32 . From Figure 20 on this occasion it is clear that the majority of the combustion chamber is close the global as the higher flow rate allowed faster mixing. From the 100 bar case of Figure 20 it is also observed that RANS predicts a larger central 'channel' of hydrogen flow towards the intake side on the vertical symmetry plane that persists throughout $310^{\circ} \mathrm{CA}$ to $330^{\circ} \mathrm{CA}$ ATDC. LES also shows this 'channel' at $310^{\circ} \mathrm{CA}$ ATDC but it predicts rapid mixing of this by $330^{\circ} \mathrm{CA}$ ATDC.

Figure 21 illustrates that for $8 \mathrm{~ms}$ injection duration and $70 \mathrm{bar}$ injection pressure the largest portion of in-cylinder area at the end of compression has mainly similar equivalence ratio to the global ratio of 0.3 (Table 3 ). For the same injection duration but with 100 bar injection pressure, the predicted RANS equivalence ratio field is spatially quite close to the global value of 0.42 , but also with some noticeable rich regions larger than 0.6. LES captured similar 'bulk' equivalence ratio maps to those of RANS and it seems that mixing was not faster than RANS at the end of compression as observed with 6ms LES and RANS in Figure 20.

Page 11 of 26 
$4.5^{\circ} \mathrm{CA}(0.5 \mathrm{~ms})$ ASOI
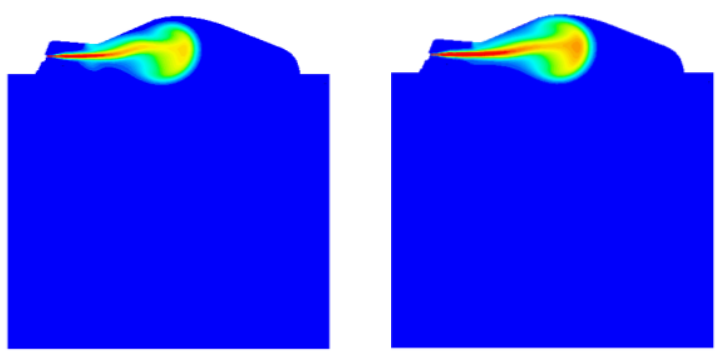

$9^{\circ} \mathrm{CA}(1 \mathrm{~ms})$ ASOI
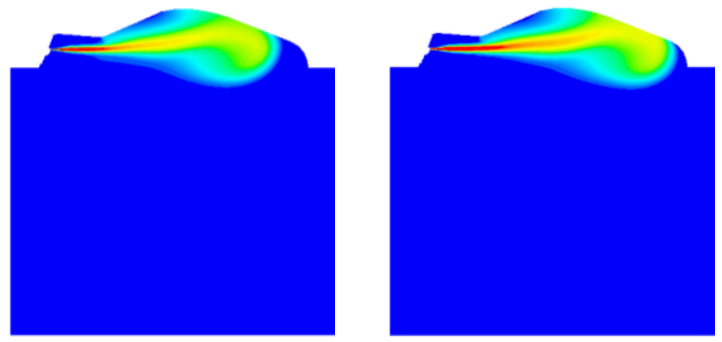

$18^{\circ} \mathrm{CA}(2 \mathrm{~ms})$ ASOI
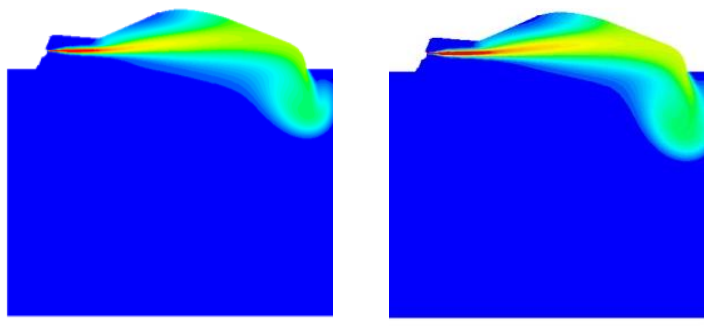

$27^{\circ} \mathrm{CA}$ (3 ms) ASOI
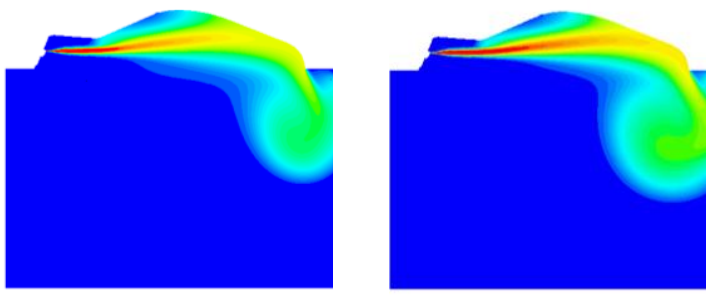

$36^{\circ} \mathrm{CA}$ (4 ms) ASOI

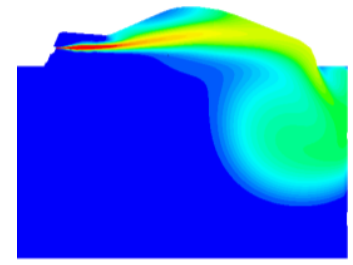

70 bar Injection

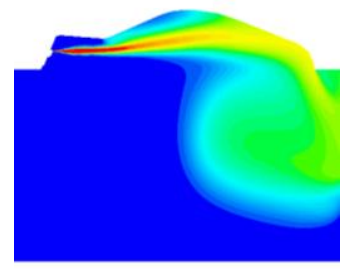

100 bar Injection
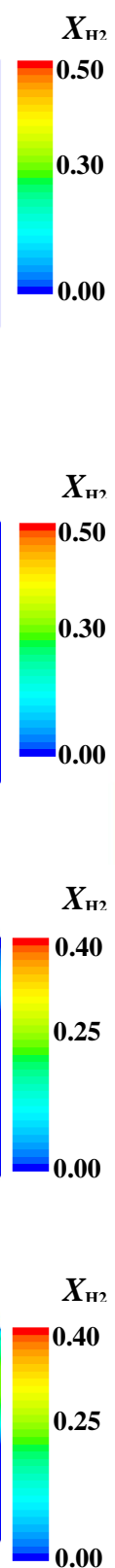

$45^{\circ} \mathrm{CA}$ (5 ms) ASOI

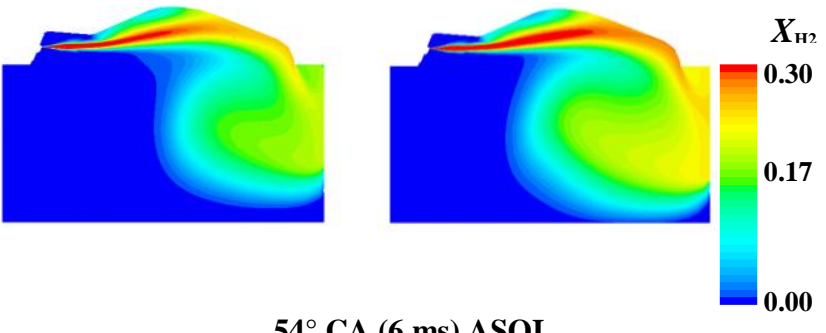

$54^{\circ} \mathrm{CA}$ (6 ms) ASOI
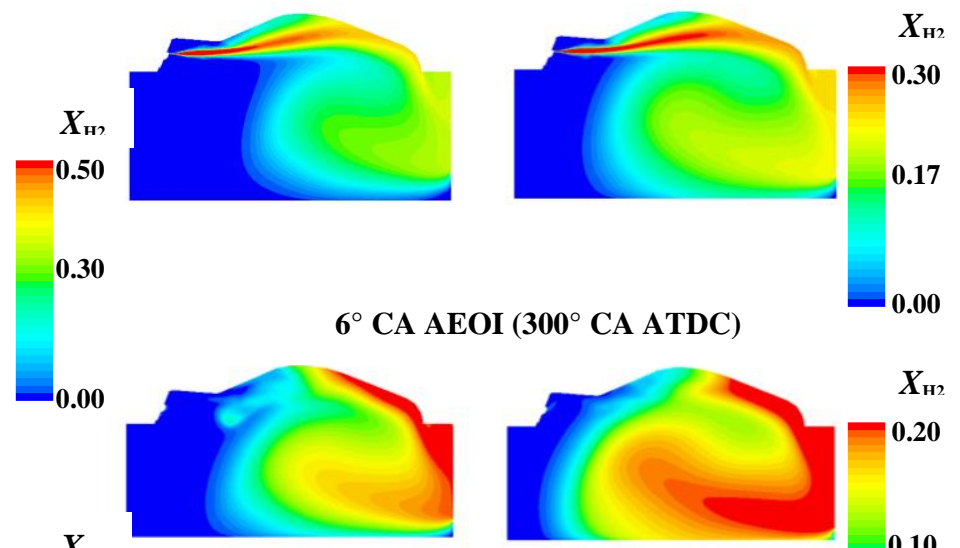

$\boldsymbol{X}_{\text {H2 }}$

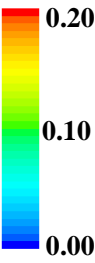

$16^{\circ} \mathrm{CA}$ AEOI $\left(310^{\circ} \mathrm{CA}\right.$ ATDC $)$

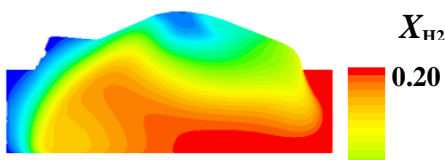

0.10

$26^{\circ}$ CA AEOI $\left(320^{\circ}\right.$ CA ATDC $) \quad 0.00$
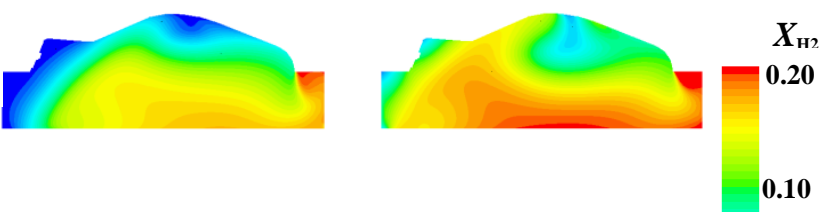

$36^{\circ} \mathrm{CA}$ AEOI $\left(330^{\circ} \mathrm{CA}\right.$ ATDC)
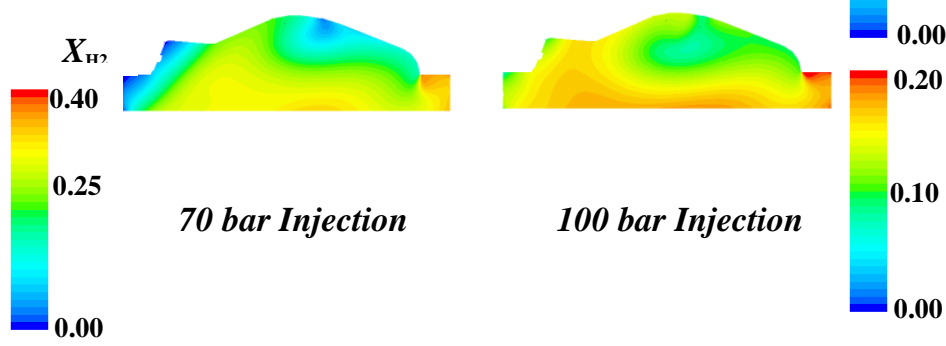

Figure 14. RANS prediction of hydrogen mole fraction $\left(X_{\mathrm{H} 2}\right)$ on the vertical tumble plane during and after the injection process; 6 ms injection duration, 70 and 100 bar injection pressure. 

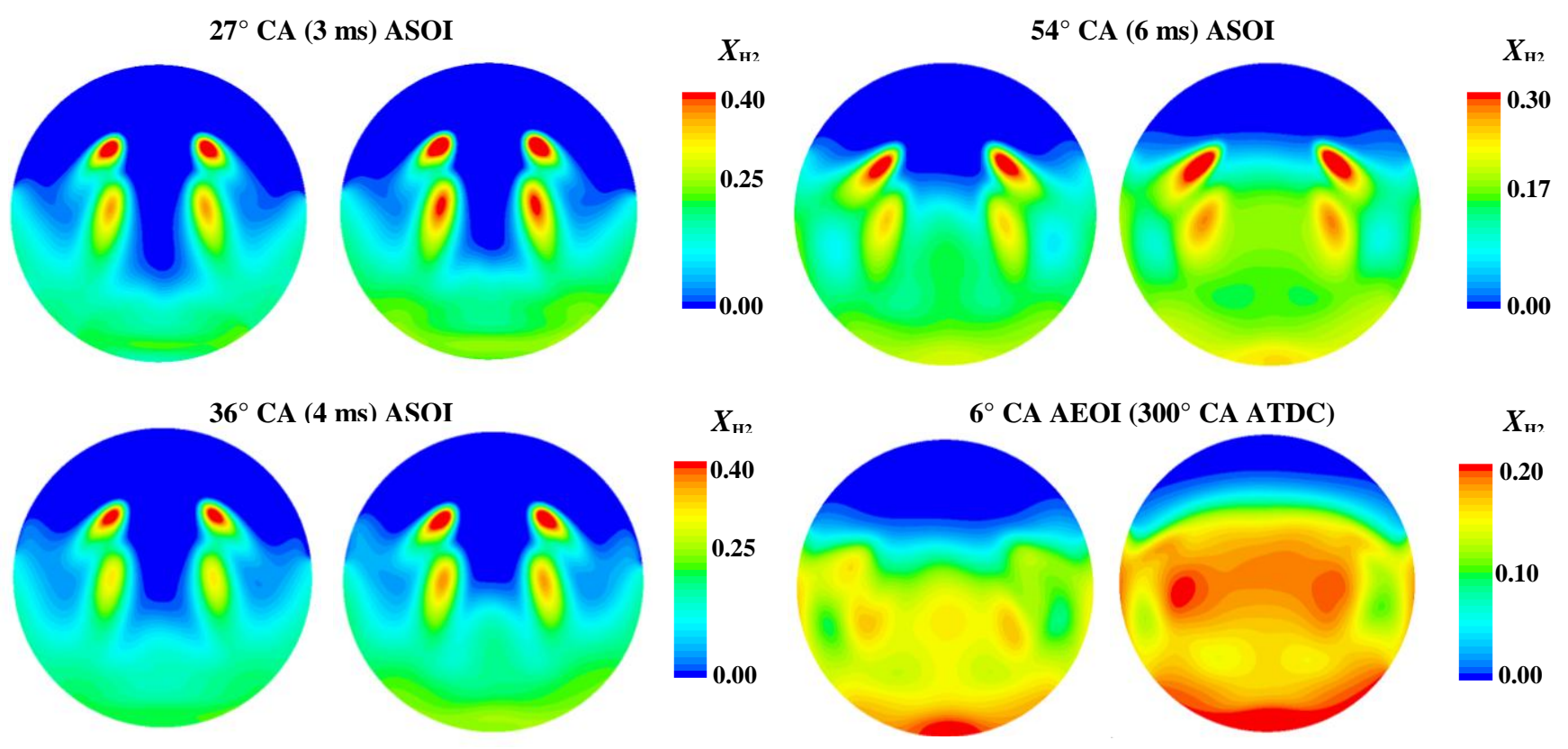

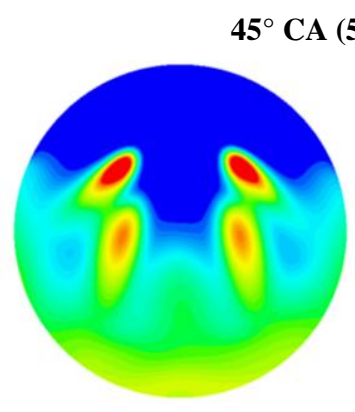

70 bar Injection

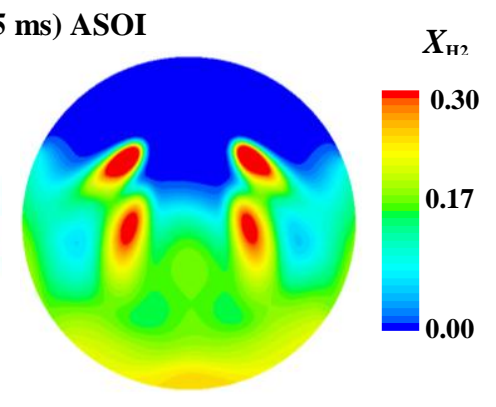

100 bar Injection

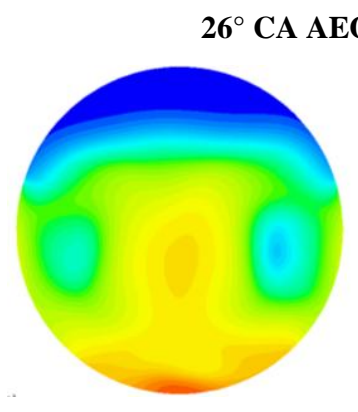

70 bar Injection

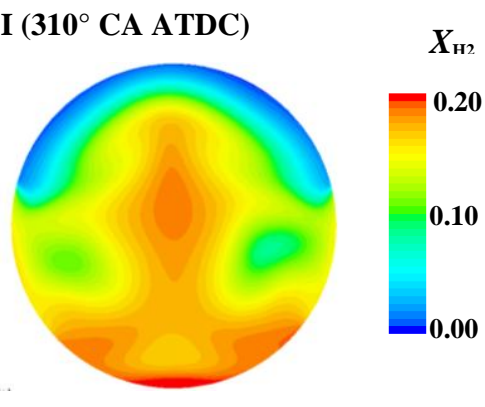

100 bar Injection

Figure 15. RANS prediction of hydrogen mole fraction $\left(X_{\mathrm{H} 2}\right)$ on the $10 \mathrm{~mm}$ horizontal plane during and after the injection process; 6 ms injection duration, 70 and 100 bar injection pressure. 
$63^{\circ} \mathrm{CA}(7 \mathrm{~ms})$ ASOI
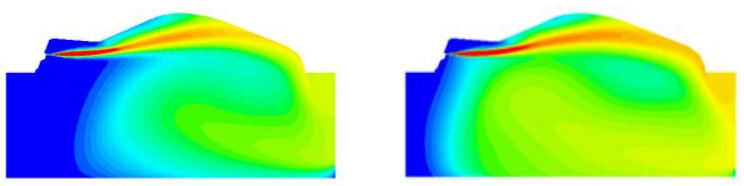

$72^{\circ} \mathrm{CA}(8 \mathrm{~ms})$ ASOI
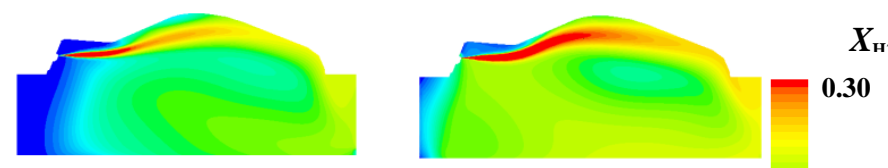

0.17

$8^{\circ}$ CA AEOI $\left(320^{\circ}\right.$ CA ATDC $)$
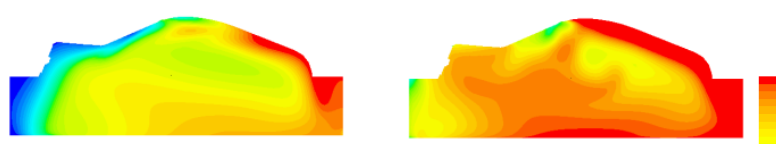

$X_{\mathrm{H}}$

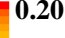

0.10

$13^{\circ} \mathrm{CA}$ AEOI $\left(325^{\circ} \mathrm{CA}\right.$ ATDC $)$
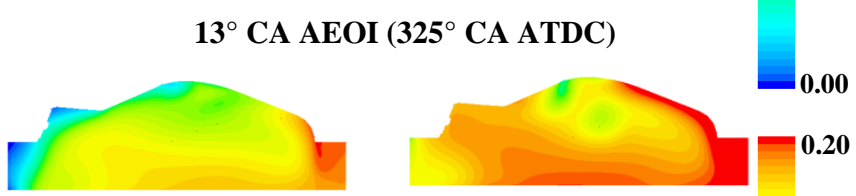

$18^{\circ}$ CA AEOI $\left(330^{\circ}\right.$ CA ATDC $)$
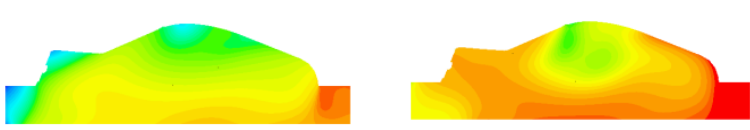

0.00

$28^{\circ}$ CA AEOI $\left(3_{40}^{\circ}\right.$ CA ATDC)
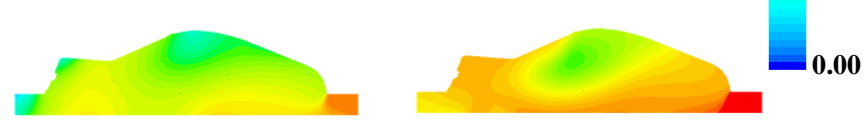

70 bar Injection

100 bar Injection
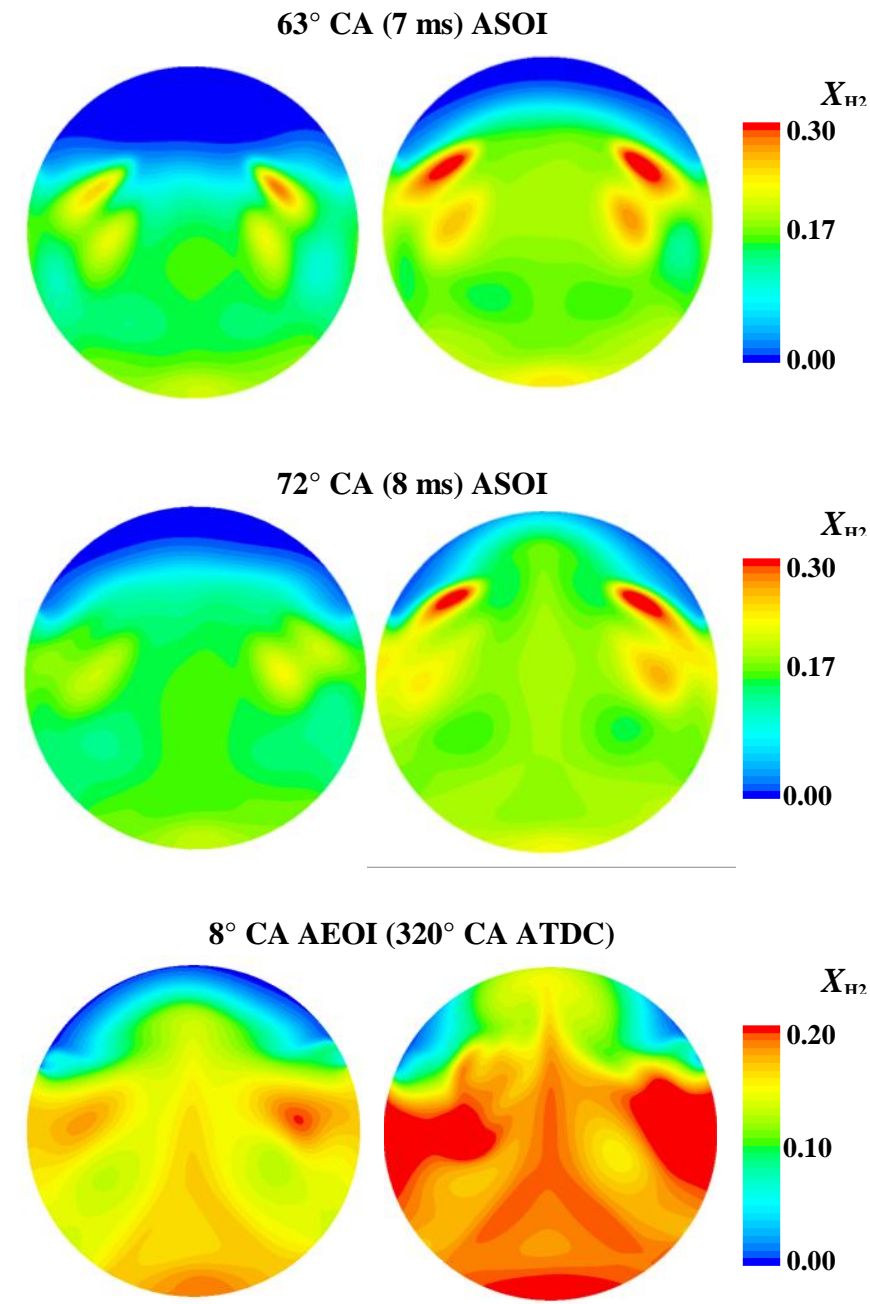

$28^{\circ}$ CA AEOI $\left(340^{\circ} \mathrm{CA}\right.$ ATDC $)$

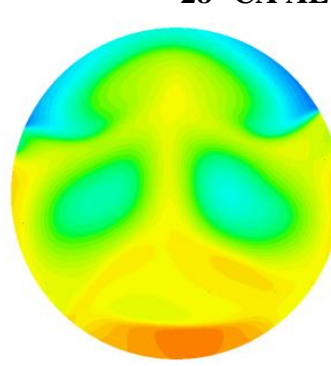

70 bar Injection

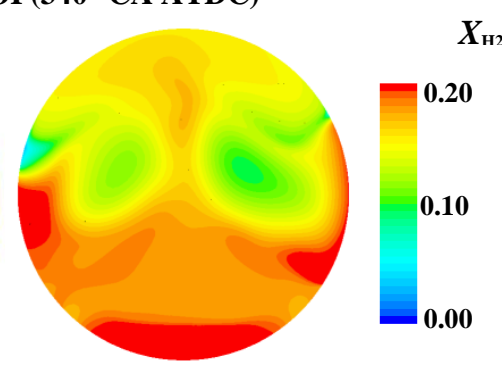

100 bar Injection

Figure 16. RANS prediction of hydrogen mole fraction $\left(X_{\mathrm{H} 2}\right)$ after the end of 8 ms injection; 70 and 100 bar injection pressure, vertical tumble plane (left), $10 \mathrm{~mm}$ horizontal plane (right). 

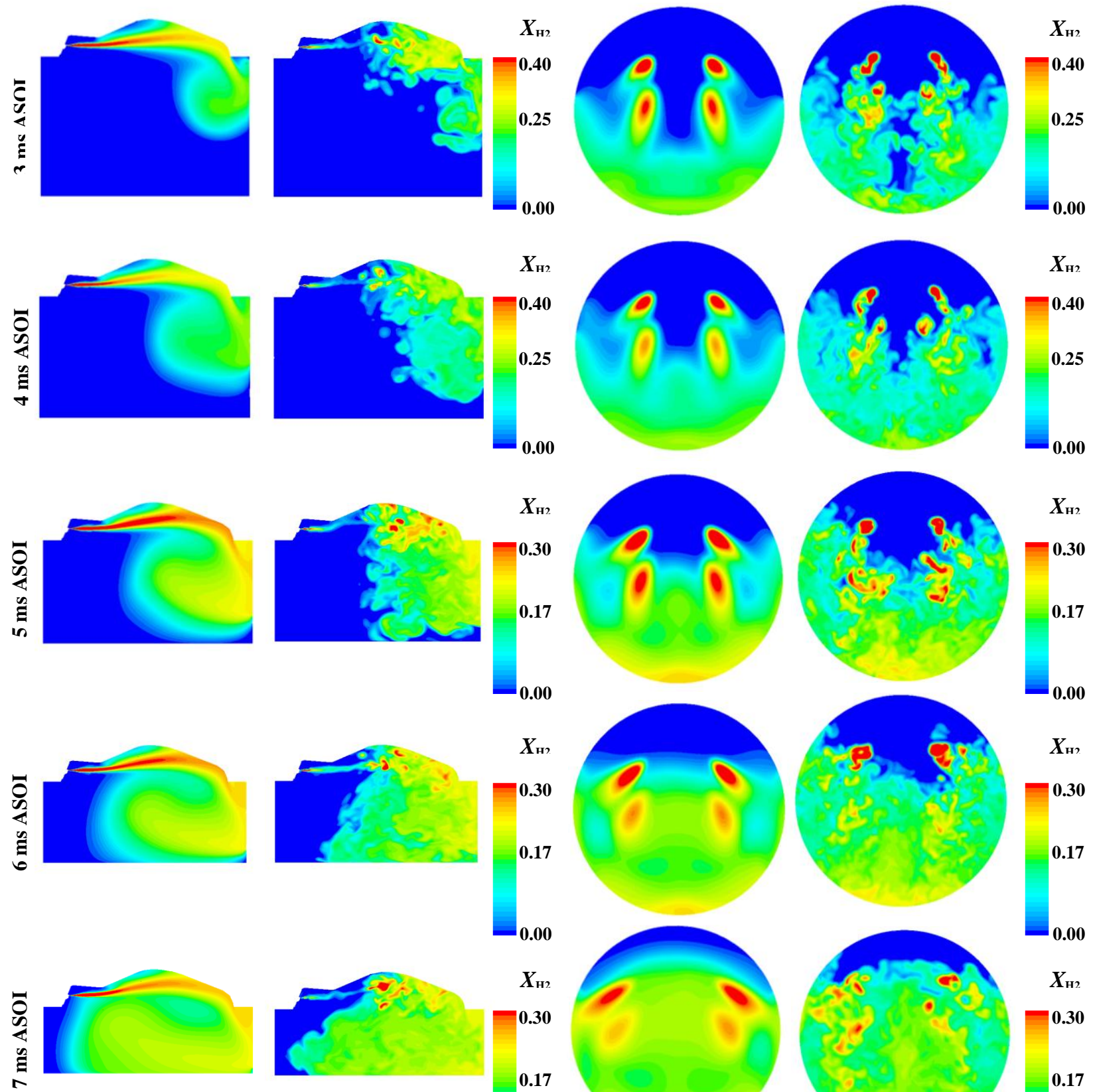

$\boldsymbol{X}_{\mathrm{H} 2}$
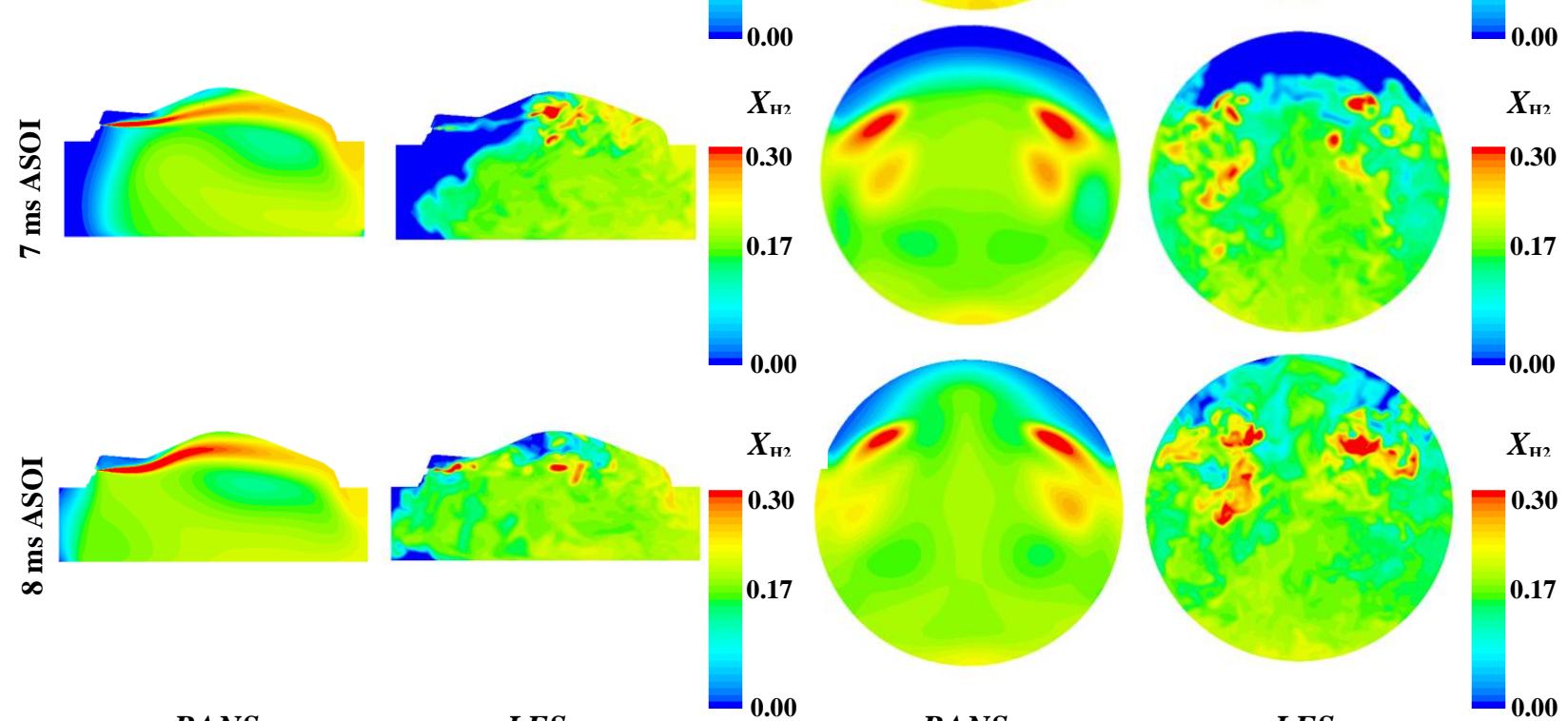

RANS

LES

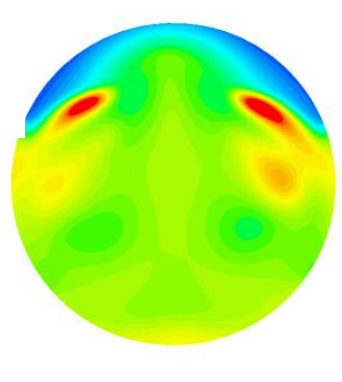

RANS

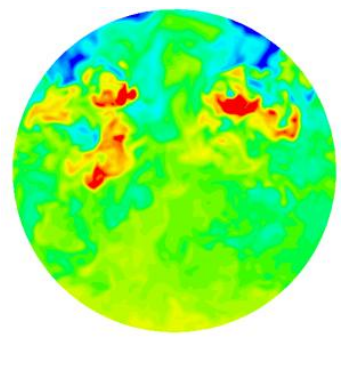

LES

Figure 17. RANS and LES predictions of hydrogen mole fraction $\left(X_{\mathrm{H} 2}\right) ; 8$ ms injection duration, 100 bar injection pressure, vertical tumble plane (left), $10 \mathrm{~mm}$ horizontal plane (right).

Page 15 of 26 
$6^{\circ} \mathrm{CA}$ AEOI $\left(300^{\circ} \mathrm{CA}\right.$ ATDC $)$
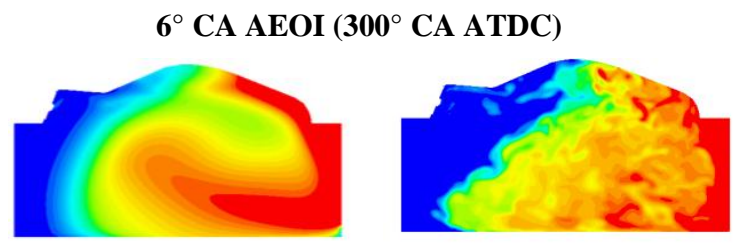

$16^{\circ}$ CA AEOI $\left(310^{\circ}\right.$ CA ATDC $)$
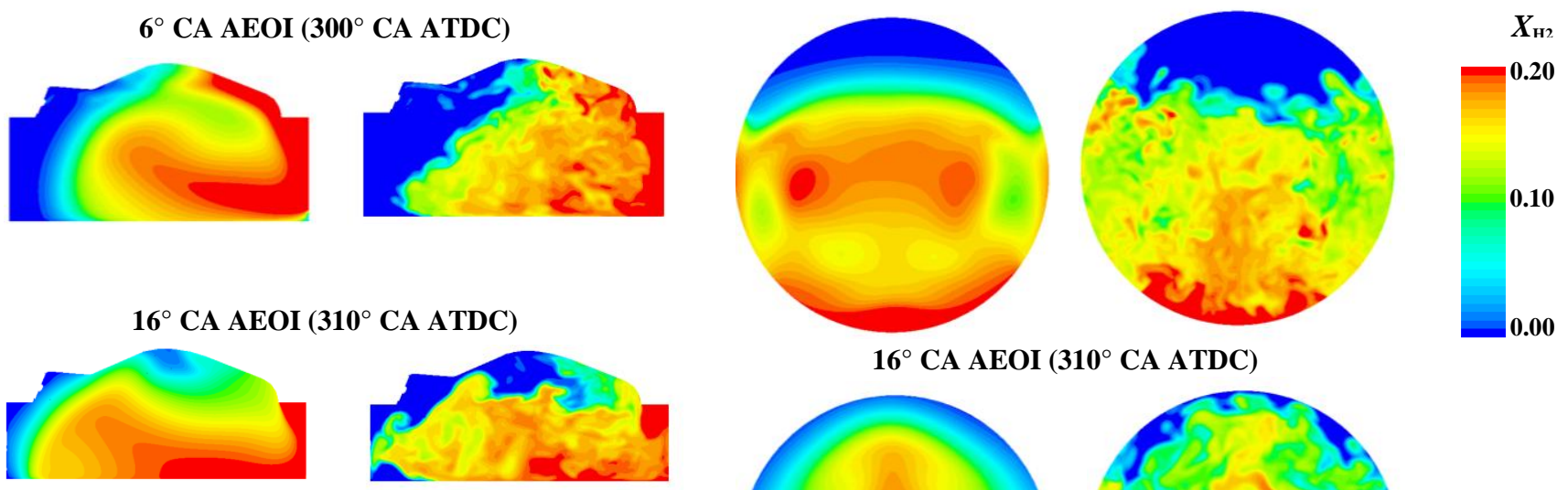

$26^{\circ}$ CA AEOI $\left(320^{\circ} \mathrm{CA}\right.$ ATDC $)$
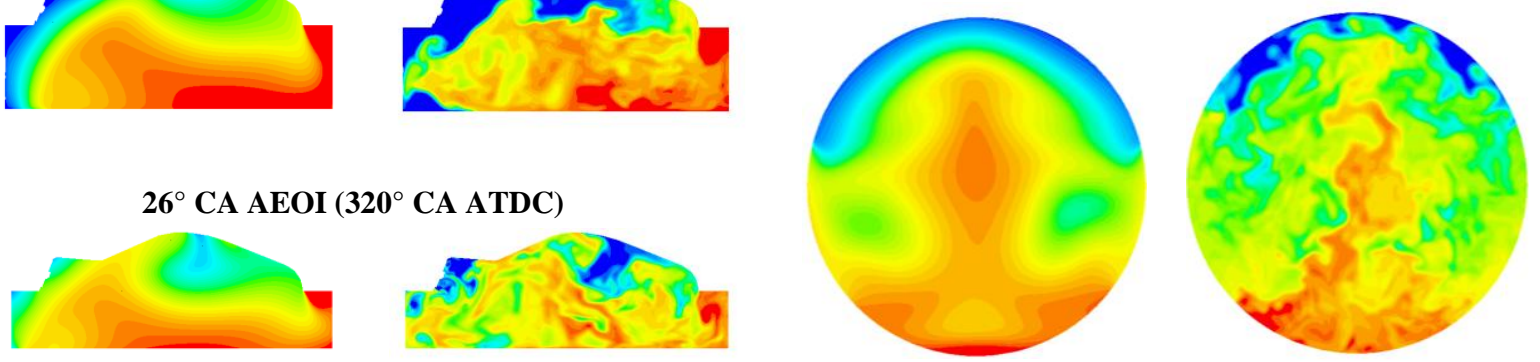

$26^{\circ} \mathrm{CA}$ AEOI $\left(320^{\circ} \mathrm{CA}\right.$ ATDC $)$

$36^{\circ}$ CA AEOI $\left(330^{\circ} \mathrm{CA}\right.$ ATDC $)$
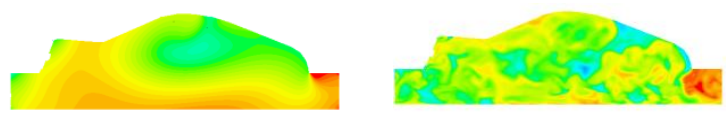

RANS

LES

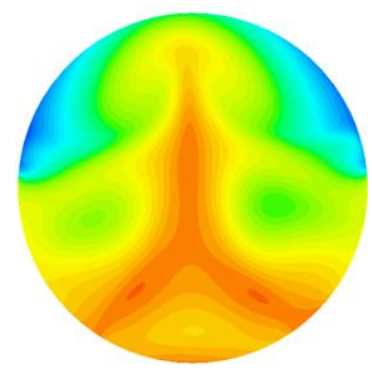

RANS

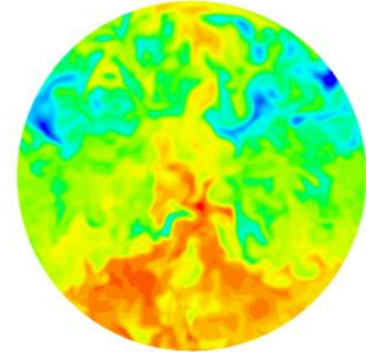

LES

Figure 18. RANS and LES predictions of hydrogen mole fraction $\left(X_{\mathrm{H} 2}\right)$ after the end of 6 ms injection; 100 bar injection pressure, vertical tumble plane (left), $10 \mathrm{~mm}$ horizontal plane (right).

$8^{\circ}$ CA AEOI $\left(320^{\circ}\right.$ CA ATDC $)$
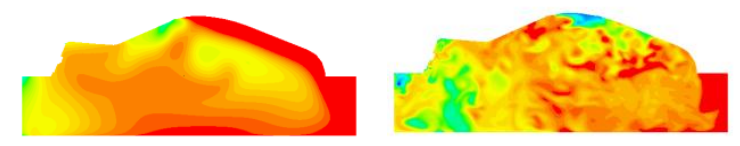

$18^{\circ}$ CA AEOI $\left(330^{\circ}\right.$ CA ATDC $)$
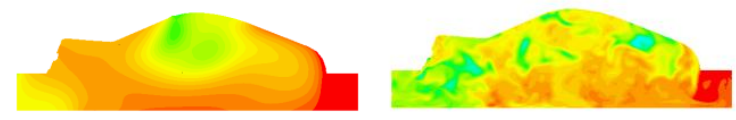

RANS

LES

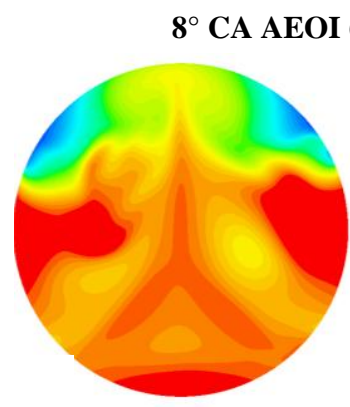

RANS
$\boldsymbol{X}_{\text {H2 }}$
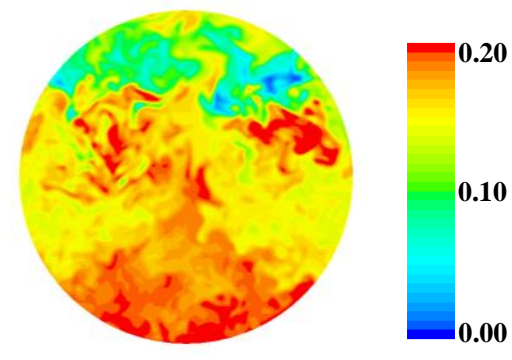

LES

Figure 19. RANS and LES predictions of hydrogen mole fraction $\left(X_{\mathrm{H} 2}\right)$ after the end of 8 ms injection; 100 bar injection pressure, vertical tumble plane (left), $10 \mathrm{~mm}$ horizontal plane (right).

Page 16 of 26 


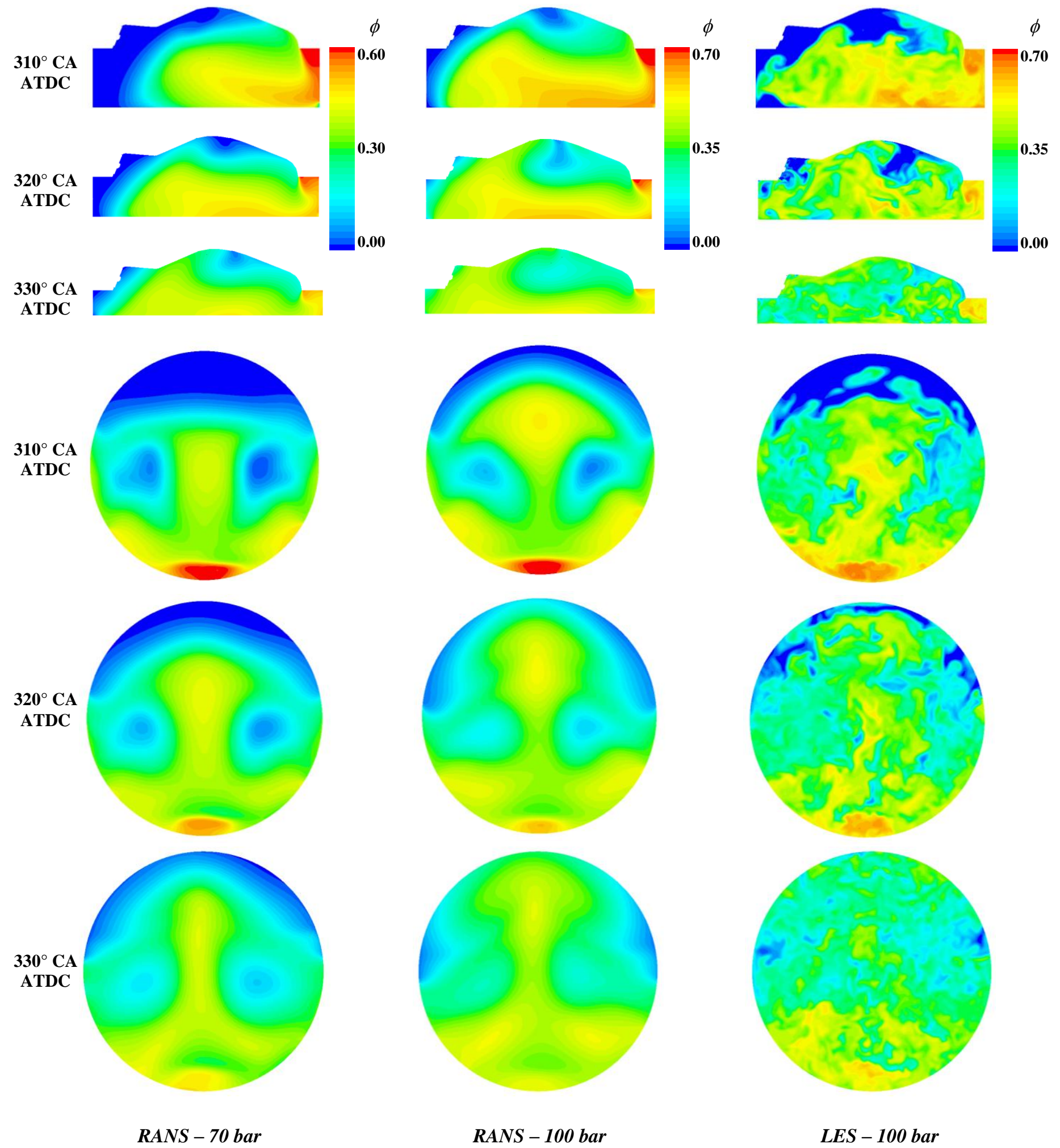

Figure 20. RANS and LES predictions of equivalence ratio close to the end of compression; 6 ms injection duration, 70 and 100 bar injection pressure, vertical tumble and $4 \mathrm{~mm}$ horizontal planes.

Page 17 of 26 


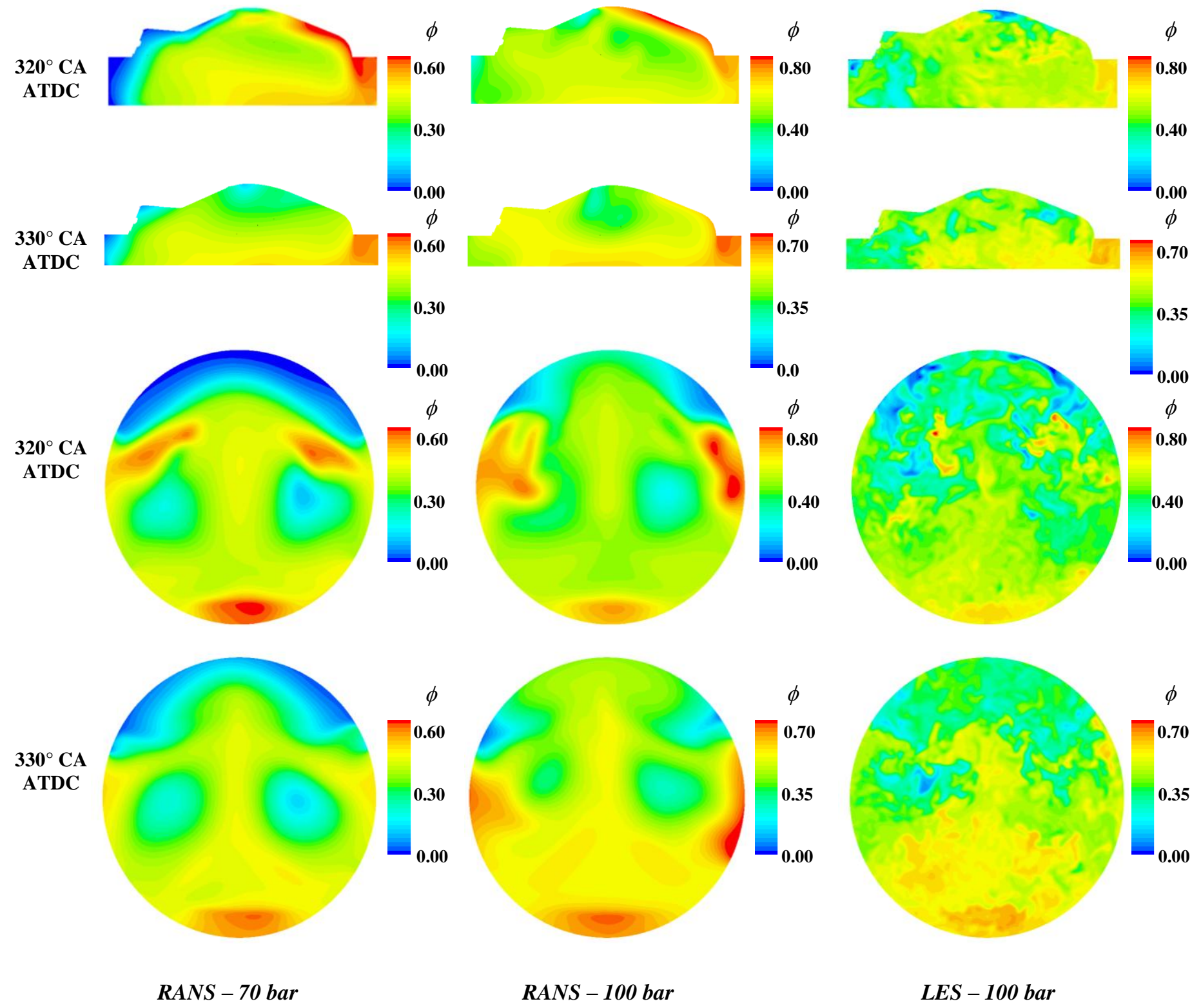

Figure 21. RANS and LES predictions of equivalence ratio close to the end of compression; 8 ms injection duration, 70 and 100 bar injection pressure, vertical tumble and $4 \mathrm{~mm}$ horizontal planes. 
Figures 22 and 23 compare velocity vector fields at the end of the compression stroke for non-fuelled and fuelled engine operation for $6 \mathrm{~ms}$ injection duration on the vertical tumble and $4 \mathrm{~mm}$ horizontal planes, respectively. The scale has been termed 'tangential velocity' as it represents the magnitude of the two components on the plane (i.e. the velocity component normal to the plane has not been included). The magnitude of the velocity components on the vertical and horizontal planes are between $0-6 \mathrm{~m} / \mathrm{s}$. It is clear that the injection of hydrogen changes the in-cylinder flow significantly. For both 70 bar and 100 bar injection (RANS) the maximum magnitude of velocity at $320^{\circ} \mathrm{CA}$ on the vertical tumble and $4 \mathrm{~mm}$ horizontal plane are $20 \mathrm{~m} / \mathrm{s}$ and $15 \mathrm{~ms}$ respectively. Injection of hydrogen yields two clockwise rotating vortices on the vertical tumble plane one inside the pent-roof close to the spark plug and one on the exhaust side close to the piston top. The pent-roof vortex transports hydrogen from the engine head toward the exhaust side while the second vortex fans out the hydrogen toward the intake side and helps forming a tumble-like circulating motion. For 100 bar injection the pent-roof vortex seems to rotate faster than the one of the 70 bar case which means that it can transport more amount of fuel in a fixed period as more fuel is present inside the domain for 100 bar injection pressure. A high velocity area is noticed in both 70 bar and 100 bar cases on the tumble plane on the intake side; this structure moves further towards the intake quenching zone for 100 bar injection than for 70 bar. At $330^{\circ}$ CA ATDC the maximum velocity magnitude is reduced to $\sim 15 \mathrm{~m} / \mathrm{s}$ on both vertical and horizontal planes. At this timing the pent-roof tumble vortex becomes clearer but the piston-top vortex seems to weaken in comparison to what observed at $320^{\circ} \mathrm{CA}$ ATDC. The latter is combined by the presence of a clearer counterclockwise vortex inside the exhaust quenching zone at the corners of the fire face on the exhaust side. (a)

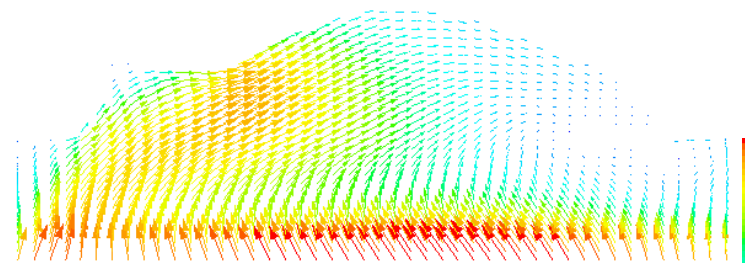

(b)

(c)

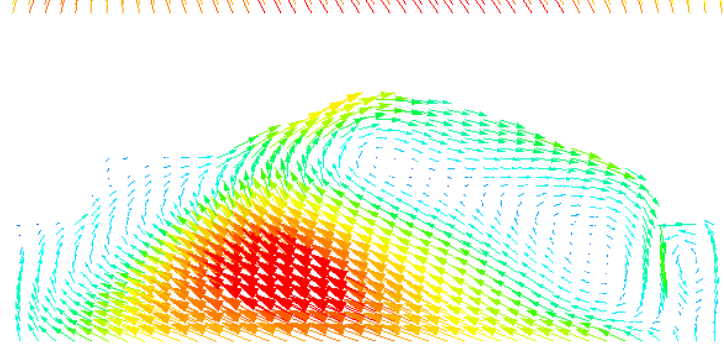

\section{Tangential} Velocity $[\mathrm{m} / \mathrm{s}]$

3
0

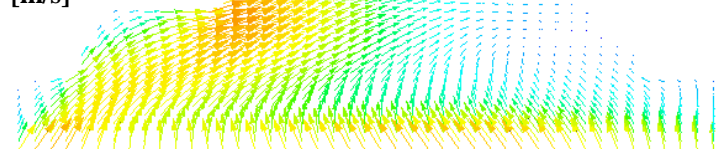

Tangential Velocity $[\mathrm{m} / \mathrm{s}]$

20

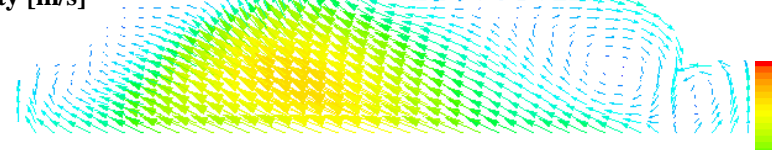

10

10

0

Tangential Velocity $[\mathrm{m} / \mathrm{s}]$

20

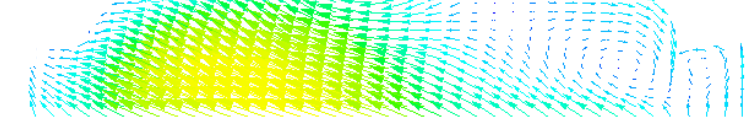

20

10

o

(d)

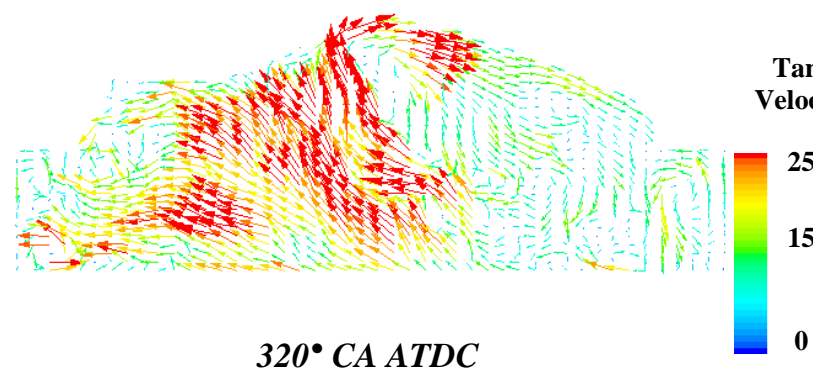

Tangential Velocity $[\mathrm{m} / \mathrm{s}]$

25

15

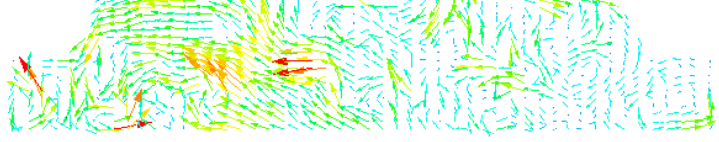

$330^{\circ} \mathrm{CA} A T D C$
Tangential Velocity $[\mathrm{m} / \mathrm{s}]$

3

o

Tangential Velocity $[\mathrm{m} / \mathrm{s}]$

20

o

0

0

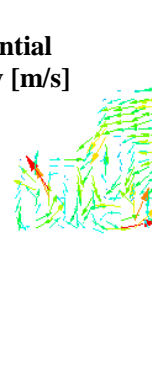

(

政
Figure 22. Velocity vectors on vertical tumble plane; (a) RANS non-fueled engine, (b) RANS 70 bar injection pressure, 6 ms injection duration (c) RANS 100 bar, 6 ms, (d) LES 100 bar, 6 ms.

Page 19 of 26 
(a)
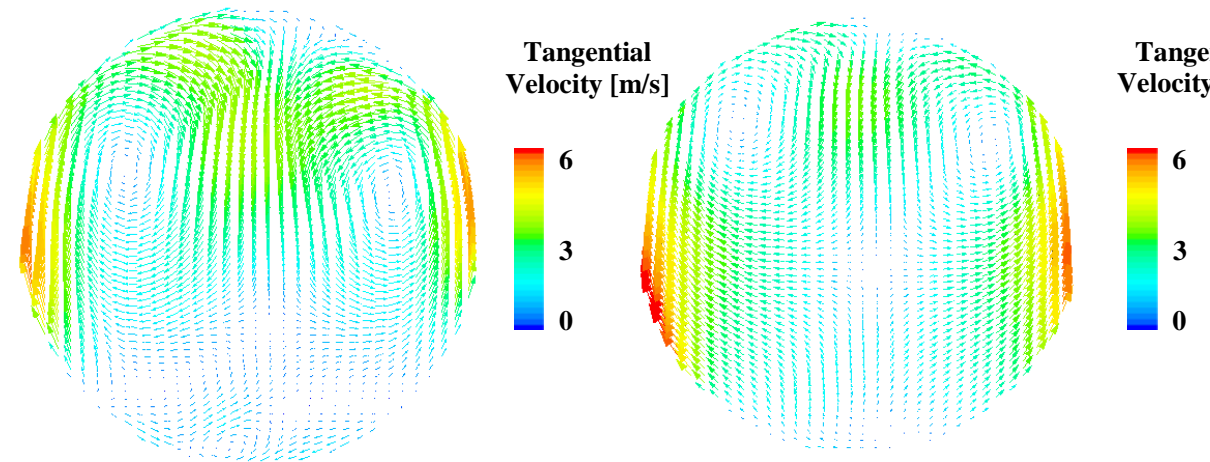

Tangential

elocity $[\mathrm{m} / \mathbf{s}]$

0

(b)

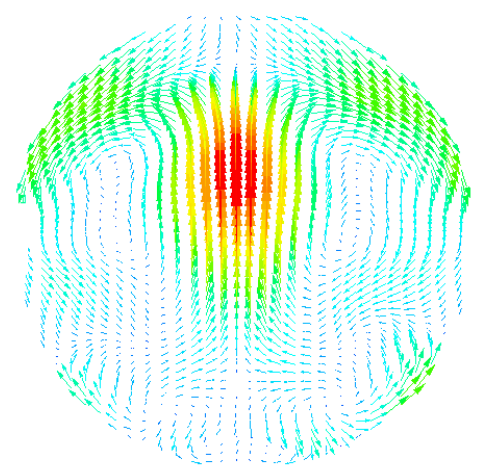

Tangentia Tangential
Velocity $[\mathrm{m} / \mathrm{s}]$

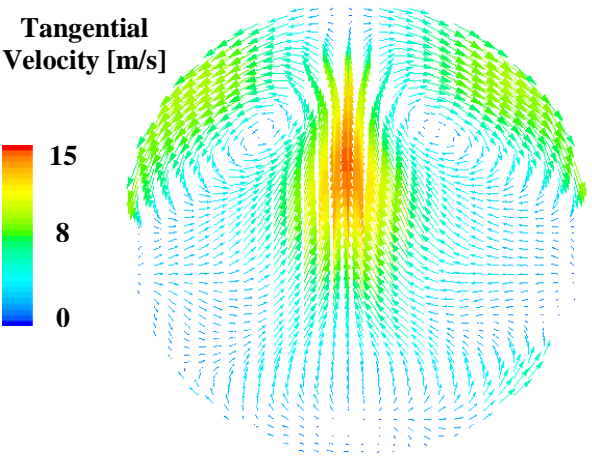

Tangential Velocity $[\mathrm{m} / \mathrm{s}]$

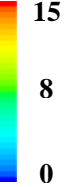

(c)
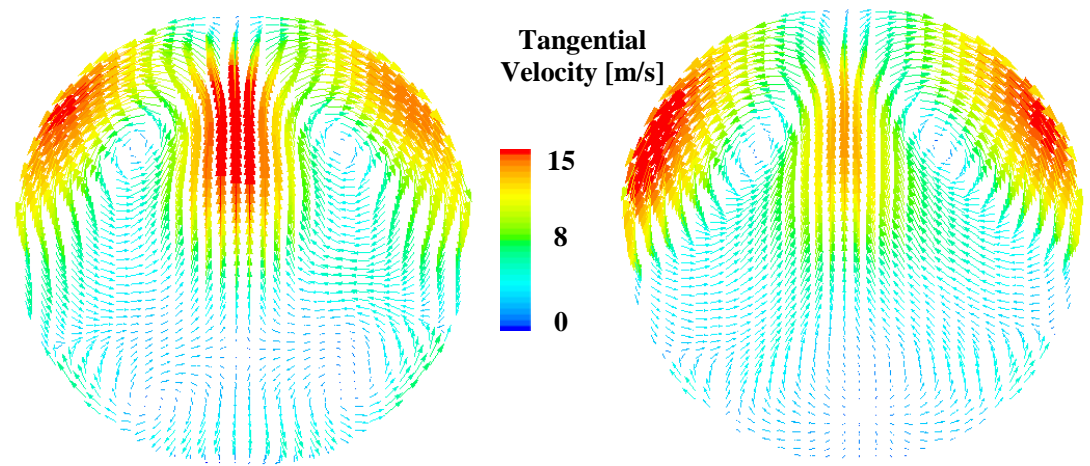

Tangential Velocity $[\mathrm{m} / \mathrm{s}]$

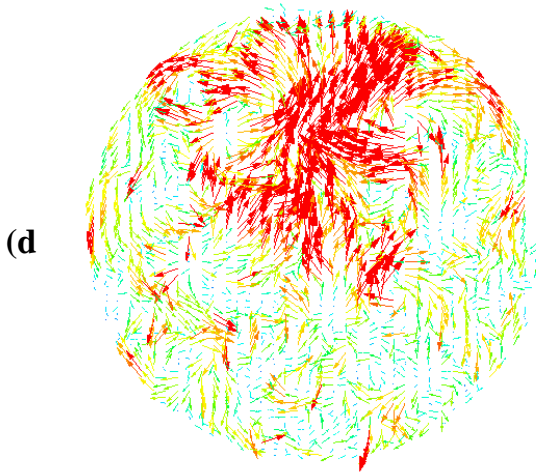

$320^{\circ} \mathrm{CA} A T D C$

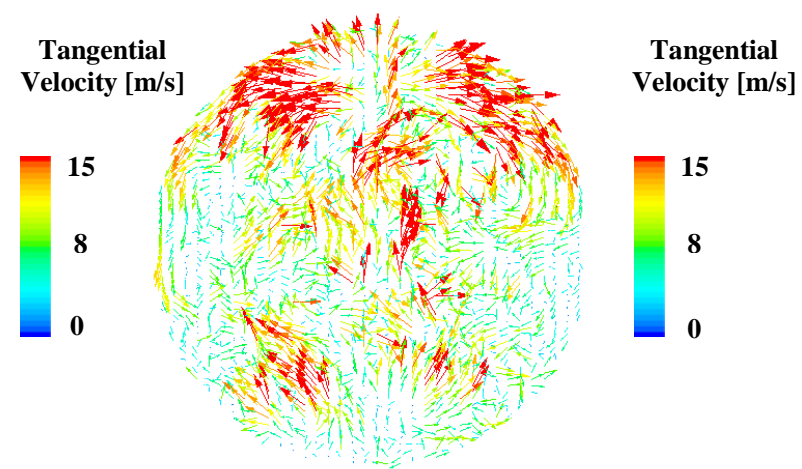

$330^{\circ} \mathrm{CA} A T D C$

Figure 23. Velocity vectors on the $4 \mathrm{~mm}$ horizontal plane; (a) RANS non-fueled engine, (b) RANS 70 bar injection pressure, $6 \mathrm{~ms}$ injection duration, (c) RANS 100 bar, $6 \mathrm{~ms}$, (d) LES 100 bar, $6 \mathrm{~ms}$. 
(a)

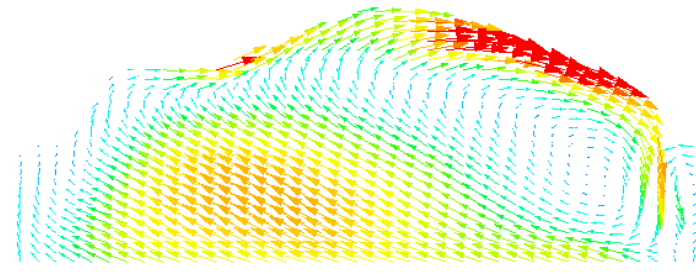

(b)

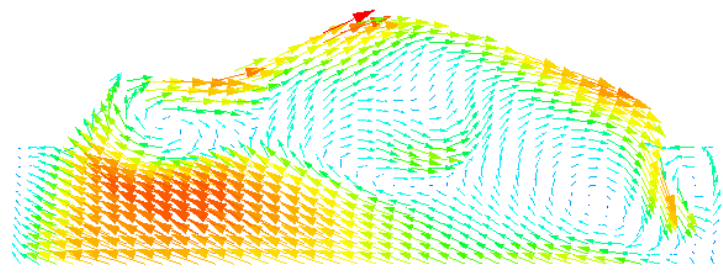

Tangential

Velocity $[\mathrm{m} / \mathrm{s}]$

Tangential

Velocity [m/s]

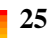

25

15

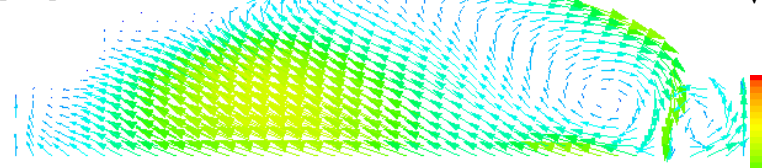

25

15

0

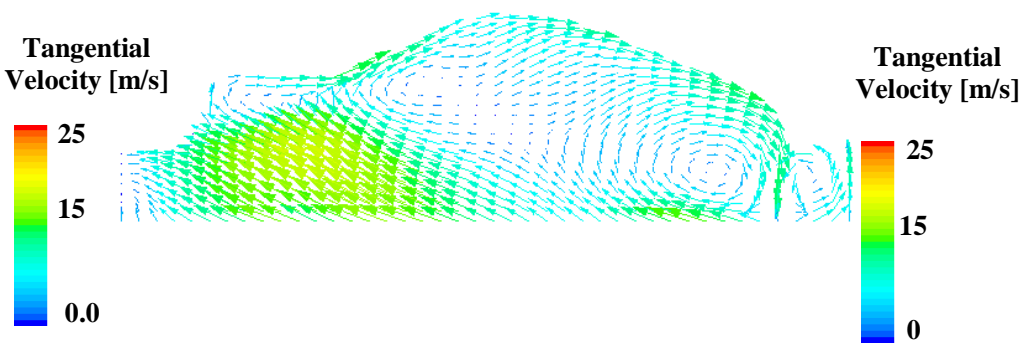

Tangential

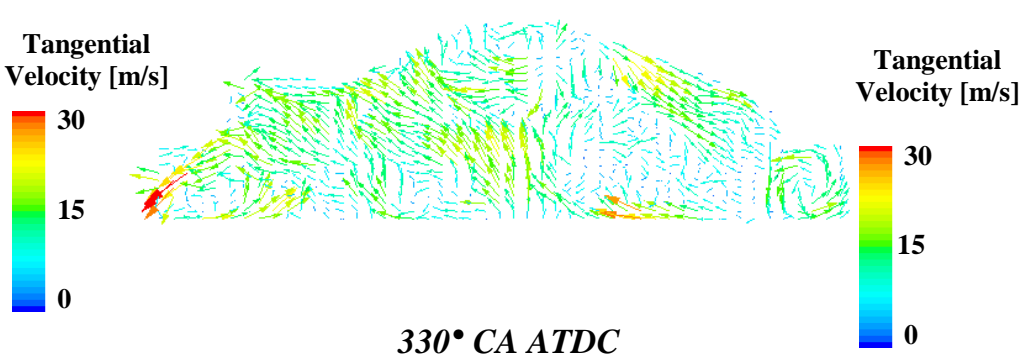

Figure 24. Velocity vectors on the vertical tumble plane for 8 ms injection duration; (a) RANS 70 bar injection pressure, (b) RANS 100 bar injection pressure, (c) LES 100 bar injection pressure.

In Figure 23 at $320^{\circ} \mathrm{CA}$ ATDC on the $4 \mathrm{~mm}$ horizontal plane a counter-rotating vortex pair operates primarily on the intake side. The counter-rotating vortex pair for 100 bar injection pressure has higher velocity than the one for 70 bar injection pressure, as indicated by the vectors on the symmetry plane and close to the wall. At $330^{\circ} \mathrm{CA}$ ATDC the velocity magnitude close to the wall was increased, and that in the middle decreased, indicating strong momentum exchange, especially for the 100 bar case.

In Figure 22, LES predicts similar bulk structure but with higher velocity magnitude than RANS on the central tumble plane, typically of the order $25 \mathrm{~m} / \mathrm{s}$. On the horizontal plane in Figure 23, the maximum velocity magnitude is the same between RANS and LES predictions. The structures of the previously described rotating vortexes on the vertical and horizontal planes are not as clear in the LES results

Figures 24-25 show the velocity vector fields at the end of the compression stroke for fuelled engine operation with $8 \mathrm{~ms}$ injection duration on the vertical tumble and $4 \mathrm{~mm}$ horizontal

Page 21 of 26 planes, respectively. On the vertical plane RANS predicts maximum velocity magnitude at $320^{\circ} \mathrm{CA}$ ATDC of $25 \mathrm{~m} / \mathrm{s}$, whilst on horizontal plane $15 \mathrm{~m} / \mathrm{s}$. For 70 bar injection only one tumble vortex can be observed on the exhaust side of the engine with centre close to the piston crown. For 100 bar injection a more complex vertical motion is observed. Specifically, a vortex is located on the exhaust side of the engine, similarly to the $6 \mathrm{~ms}$ injection case, and another vortex is located under intake side between the two valves. The interaction between the streams fanned by the exhaust side, with the streams produced by the intake side vortex, causes strong streams toward the pent-roof wall on the exhaust side.

On the horizontal plane at $320^{\circ} \mathrm{CA}$ ATDC in Figure 25 a pair of counter-rotating vortices is not as clearly formed as that shown in Figure 23. However, the vortex pair does become visible at $330^{\circ} \mathrm{CA}$ ATDC and similar flow momentum exchange can be observed to that in Figure 23. LES predicts $\sim 5 \mathrm{~m} / \mathrm{s}$ larger peak velocity magnitude than RANS on the tumble plane, but on the horizontal plane the differences in maximum velocity magnitude between RANS and LES are much smaller. 
(a)
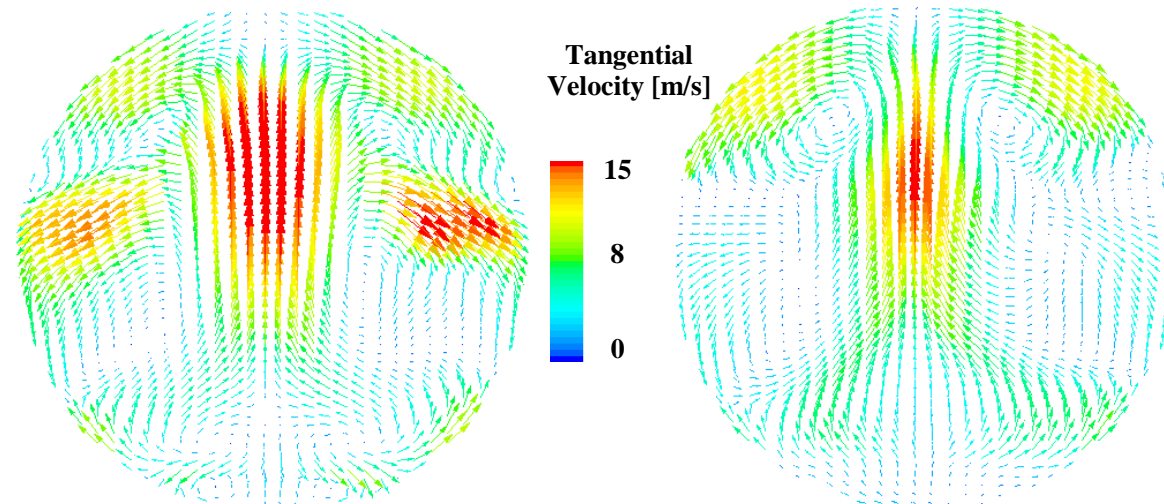

\author{
Tangential \\ Velocity $[\mathrm{m} / \mathrm{s}]$
}

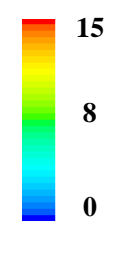

(b)
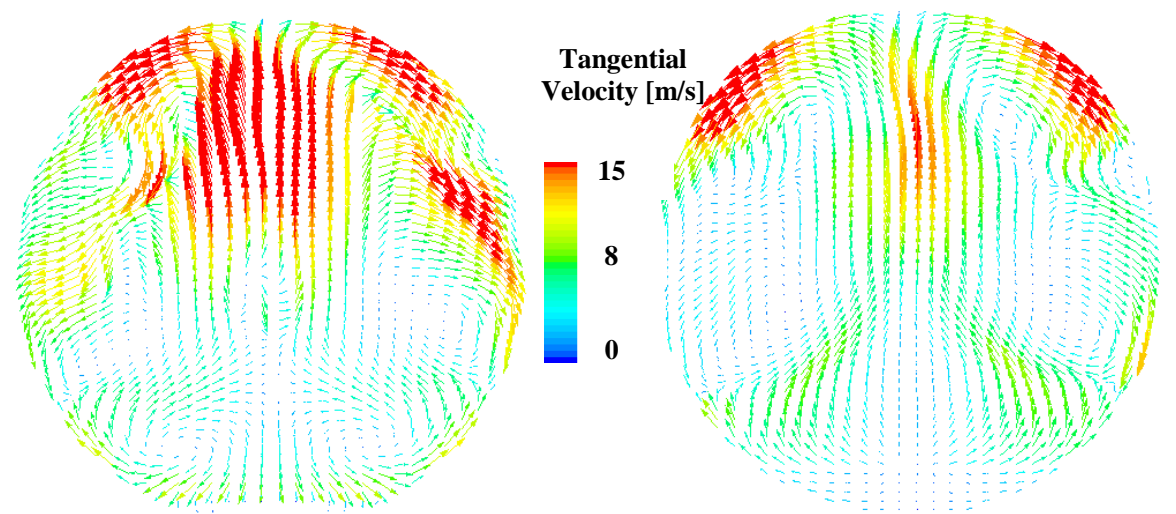

Tangential

Velocity $[\mathrm{m} / \mathrm{s}]$

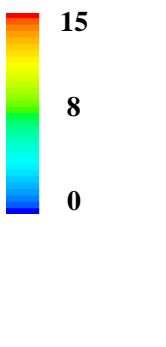

(c)

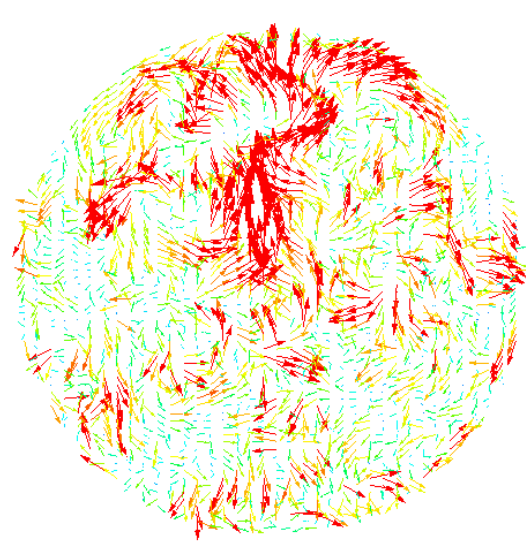

$320^{\circ} \mathrm{CA} A T D C$

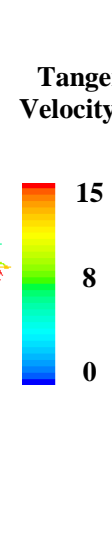

15

8

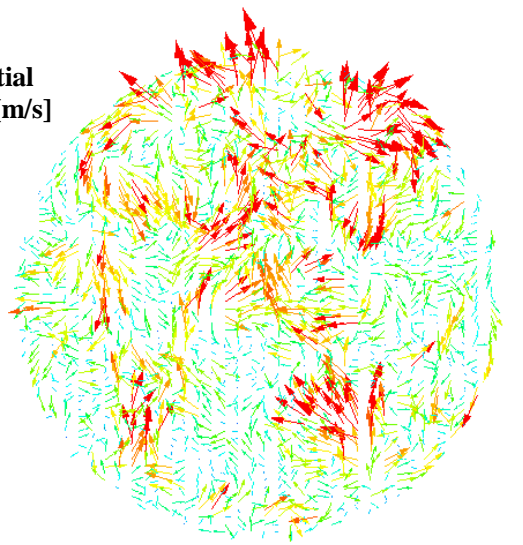

$330^{\circ} C A A T D C$

Figure 25. Velocity vectors on the $4 \mathrm{~mm}$ horizontal plane for $8 \mathrm{~ms}$ injection duration; (a) RANS 70 bar injection pressure, (b) RANS 100 bar injection pressure, (c) LES 100 bar injection pressure. 


\section{CONCLUSIONS}

The present work focused on computational studies of hydrogen jets and mixture formation using RANS and LES. Different injection pressures and injector nozzles were studied in a quiescent environment. Additionally, different injection pressures and durations were simulated in an engine operating at 1500 RPM with 1.5 bar intake pressure. The main conclusions of this work can be summarized as follows:

- LES resolves the shock structures close to the nozzle in sharper detail than RANS on an identical computational grid. LES predicts higher number of barrel-shape shocks than RANS does after the Mach disk. LES also predicts jet-air interaction phenomena close to the jet boundary that RANS does not, including mixing related to the strong initial shock. Although no hydrogen experimental data were available for direct comparison, the LES prediction of hydrogen-air mixing was found qualitatively comparable with experimental results available in the literature for other gases. It is also clear that grid density is critical in resolving such complex flow features and beneficial even with RANS.

- With large injection to ambient pressure ratio ( 67), RANS predicted higher jet penetration than LES while for lower ratio $(\sim 17)$, LES predicted longer penetration. This may be due to the fact that, unlike RANS, LES was able to resolve the shock structure and spatial jet fluctuations in the radial direction, particularly in first $20 \mu$ s ASOI.

- The stepped-shape design of the injector nozzle was found to introduce two main effects. First, it restricted expansion of the hydrogen jet just after the inner nozzle-hole exit. This caused a smaller Mach disk and narrower underexpanded jet. Secondly, it led to higher axial penetration than the straight fixed diameter nozzle design.

- In-cylinder hydrogen injection with a 6-hole asymmetric side injector showed multiple hydrogen jet impingements onto the opposite cylinder wall and piston crown. These were prominent factors in mixture formation with both 70 bar and 100 bar injection pressure, using injection timing soon after intake valve closure and either $6 \mathrm{~ms}$ or $8 \mathrm{~ms}$ injection duration. Typically the areas close to walls on the exhaust side were richer in fuel.

- In-cylinder LES demonstrated details of local hydrogenair mixing structures. However, considering that running LES and, in particular, averaging over many cycles can be too computationally expensive, RANS can be used to achieve an initial understanding of the mixing processes in hydrogen-fuelled engines. The 'bulk' shape of the fuel cloud structure and motion, both during injection and after the end of the injection were predicted with RANS similarly to LES.

- With $6 \mathrm{~ms}$ injection duration, the area downstream of the injector turned out to be nearly devoid of hydrogen soon after the end of injection and took longer to mix with the already injected hydrogen. For $8 \mathrm{~ms}$ duration though, the hydrogen cloud had already recirculated and reached the injector vicinity by the end of injection.

- With the injection strategies employed, even with 100 bar injection pressure and $8 \mathrm{~ms}$ injection duration it was not possible to achieve a fairly homogenous mixture at the close to the end of compression. Further optimisation is needed to obtain a suitable in-cylinder fuel concentration map at ignition timing.

- The process of hydrogen injection changed the in-cylinder flow field significantly. Close to the end of compression a stronger tumble structure was observed than without injection; peak in-cylinder velocities were of the order 20 $\mathrm{m} / \mathrm{s}$ whilst for the non-fuelled engine peak values of just 5-6 m/s were recorded. Similarly, on horizontal planes, stronger counter-rotating vortical structures were observed than in the case without fuelling.

- LES captured higher instantaneous velocity magnitude than RANS by about $5 \mathrm{~m} / \mathrm{s}$ and the main 'average' flow structures of the RANS velocity field were not always as clearly distinguished in the LES velocity fields. This highlights the need for multi-cycle LES for direct comparison with RANS but also the potential for studying cyclic variability effects in hydrogen engines using LES.

Current work is focused on other injection strategies and intake pressure conditions for optimisation of in-cylinder mixture formation. Injector nozzle designs also require optimisation. For example, it is believed that with latest manufacturing methods, e.g. Laser drilling, the shape of the internal geometry of the hole can also be individually designed to achieve optimised hydrogen jetting, penetration and mixing characteristics. In terms of methodology, various real gas equations of state are being implemented and sensitivity of the results to those is being studied. Higher spatial and temporal resolution of LES is also under investigation for shock capturing and subsequent mixing.

\section{REFERENCES}

1. Bokris, J., O’M., “The Origin of Ideas on a Hydrogen Economy and its Solution to the Decay of the Environment," Int. J. Hydrogen Energy, 27:731-740, 2002.

2. Verhelst, S., Wallner, T., "Hydrogen-Fuelled Internal Combustion Engines," Progress in Energy and Combustion Science, 35:490-527:2009. 
3. Roy, M.K., Kawahara, N., Tomita, E., Fujitani, T., "HighPressure Hydrogen Jet and Combustion Characteristics in a Direct-Injection Hydrogen Engine," SAE Int. J. Fuels Lubr. 5(3):1414-1425, 2012, 2011.

4. Aleiferis, P.G., Rosati, M.F., "Flame Chemiluminescence on OH LIF Imaging in a Hydrogen-Fuelled Spark-Ignition Engine," Int. J. Hydrogen Energy, 37:1797-1812:2012.

5. Knop, V., Benkenida, A., Jay, S., Colin, O., "Modelling of Combustion and Nitrogen Oxide Formation in HydrogenFuelled Internal Combustion Engines within a 3D CFD Code," Int. J. Hydrogen Energy, 33:5083-5097:2008.

6. Rakopoulos, C.D., Kosmadakis, G.M., Pariotis, E.G., "Evaluation of a Combustion Model for the Simulation of Hydrogen Spark-Ignition Engines Using a CFD Code," Int. J. Hydrogen Energy, 35:12545-12560:2010.

7. Rakopoulos, C.D., Kosmadakis, G.M., Demuynck, J., De Paepe, M., Verhelst, S., "A Combined Experimental and Numerical Study of Thermal Processes, Performance and Nitric Oxide Emissions in a Hydrogen-Fuelled Spark Ignition Engine," Int. J. Hydrogen Energy, 36:51635180:2011.

8. Zhenzhong, Y., Lijum, W., Manlou, H., Yongdi, C., "Research on Optimal Control to Resolve The Contradictions Between Restricting Abnormal Combustion and Improving Power Output in Hydrogen Fuelled Engines," Int. J. Hydrogen Energy, 37:774782:2012.

9. Nobuyuki, K., Tomita, E., "Visulization of Auto-Ignition and Pressure Wave during Knocking in a Hydrogen Spark-Ignition Engine," Int. J. Hydrogen Energy, 34:3156-3163:2009.

10. Li, H., Karim, G.A., "Knock in Spark Ignition Hydrogen Engines,” Int. J. Hydrogen Energy, 29:859-865:2004.

11. Wallner, T., Nande, A., and Naber, J., "Evaluation of Injector Location and Nozzle Design in a Direct-Injection Hydrogen Research Engine," SAE Technical Paper 200801-1785, 2008.

12. Scarcelli, R., Wallner, T., Salzar, V.M., Kaiser, S.A., "Modelling and Experiments of Mixture Formation in a Hydrogen Direct-Injection Research Engine," SAE Int. J. Engines, 2(1):530-541, 2010.

13. Owston, R., Magi, R., Abraham, J., "Fuel-Air Mixing Characteristics of DI Hydrogen Jets," SAE Int. J. Engines, 1(1):693-712, 2009,

14. Rosati, M. and Aleiferis, P.G., "Hydrogen SI and HCCI Combustion in a Direct-Injection Optical Engine," $S A E$ Int. J. Engines 2(1):1710-1736, 2009.

15. Kaiser, S., White, C.M., "PIV and PLIF to Evaluate Mixture Formation in a Direct Injection Hydrogen-Fuelled Engine," SAE Int. J. Engines, 1:657-668, 2009.
16. Salazar, V. and Kaiser, S., "An Optical Study of Mixture Preparation in a Hydrogen-Fuelled Engine with Direct Injection Using Different Nozzle Designs," SAE Int. J. Engines 2(2):119-131, 2010.

17. Scarcelli, R., Wallner, T., Matthias, N., Salazar, V., Kaiser, S., "Mixture Formation in Direct Injection Hydrogen Engines: CFD and Optical Analysis of Singleand Multi-Hole Nozzles," SAE Int. J. Engines 4(2):23612375, 2011.

18. Lynch, F.E., "Parallel Induction: A Simple Fuel Control Method for Hydrogen Engines," Int. J. Hydrogen Energy, 8:721-730:1983.

19. Furuhama, S., Fukuma, T., "High Output Power Hydrogen Engine with High Pressure Fuel Injection, Hot Surface Ignition and Turbocharging" Int. J. Hydrogen Energy, 6:399-407: 1986.

20. Prabhu Kumar, G.P., Nagalingam, B., Gopalakrishnan, K.V., "Theoretical Studies of a Spark-Ignited Supercharged Hydrogen Engine" Int. J. Hydrogen Energy, 10:389-397:1985.

21. Berckmüller, M., Rottengruber, H., Eder, A., Brehm, N., Elsässer, G., Müller-Alander, G., Schwarz, C., "Potentials of a Charged SI-Hydrogen Engine," SAE Technical Paper 2003-01-3210, 2003.

22. Al-Baghdadi, M.S., Al-Janabi, H.S., "A Prediction Study of a Spark Ignition Supercharged Hydrogen Engine," Energy Conversion and Management, 44:31433150:2003.

23. Verhelst, S., Sierens, R., "Combustion Studies for PFI Hydrogen IC Engines," SAE Technical Paper 2007-013610, 2007.

24. Verhelst, S., Maesschalck, P., Rombaut, N., Sierens, R., "Increasing the Power Output of Hydrogen Internal Combustion Engines by Means of Supercharging and Exhaust Gas Recirculation," Int. J. Hydrogen Energy, 34:4406-4412:2009.

25. Wallner, T., Lohse-Busch, H., Shidore, N., "Operating Strategy for a Hydrogen Engine for Improved DriveCycle Efficiency and Emissions Behaviour," Int. J. Hydrogen Energy, 34:4617-4625:2009.

26. Roy, M.M., Tomita, E., Kawahara, N., Harada, Y., Sakane, A., "Performance and Emissions of a Supercharged Dual-Fuel Engine Fuelled by HydrogenRich Coke Oven Gas," Int. J. Hydrogen Energy, 34:96289638:2009.

27. Roy, M.M., Tomita, E., Kawahara, N., Harada, Y., Sakane, A., "An Experimental Investigation on Engine Performance and Emissions of a Supercharged $\mathrm{H}_{2}$-Diesel Dual-Fuel Engine," Int. J. Hydrogen Energy, 35:844853:2010. 
28. Roy, M.M., Tomita, E., Kawahara, N., Harada, Y., Sakane, A., "Comparison of Performance and Emissions of a Supercharged Dual-Fuel Engine Fuelled by Hydrogen and Hydrogen-Containing Gaseous Fuels," Int. J. Hydrogen Energy, 36:7339-7352:2011.

29. Ohira, T., Nakagawa, K., Yamane, K., Kawanabe, H., Shioji, M., "Feasibility Study of Emission Control of Hydrogen Fuelled SI Engine", Proceedings of IMechE International Conference on Internal Combustion Engines: Performance, Fuel Economy and Emissions, pp. 199-209, December 11-12, London, 2007.

30. Nakagawaa, K., Yamanea, K., Ohira, T., "Potential of Large Output Power, High Thermal Efficiency, Near-zero NOx Emission, Supercharged, Lean-burn, Hydrogenfuelled, Direct Injection Engines," Energy Procedia, 29:455-462:2012.

31. Donaldson, C., Snedeker, S., "A Study of Free Jet Impingement. Part 1. Mean Properties of Free and Impingement Jets," J. Fluid Mech, 45:281-319:1971.

32. Munday, D., Gutmark, E., Liu, J., Kailasanath, K., "Flow Structure and Acoustics of Supersonic Jets from Conical Convergent-Divergent Nozzles," Physics of Fluids, 23:116102:2011.

33. Panda, J., Seasholtz, R.G., "Measurement of Shock Structure and Shock-Vortex Interaction in UnderExpanded Jets Using Rayleigh Scattering," Physics of Fluids, 11:3761:1999.

34. White, T.R., Milton, B.E., "Shock Wave Calibration of Under-Expanded Natural Gas Fuel Jets," Shock Waves, 18:353-364:2008.

35. Yu, J., Vuorinen, V., Hillamo, H., Sarjovaara, T., Kaario, O., Larmi, M., “An Experimental Study on High Pressure Pulsed Jets for DI Gas Engine Using Planar Laser-Induced Fluorescence," SAE Technical Paper 2012-01-1655, 2012.

36. Dauptain, A., Cuenot, B., Gicquel, Y.M., "Large-Eddy Simulation of a Stable Supersonic Jet Impinging on Flat Plate," AIAA J, 48(10): 2325-2337:2010.

37. Kim, J., Choi, H., "Large Eddy Simulation of a Circular Jet: Effect of Inflow Conditions on the Near Field," $J$. Fluid Mech, 620:383-411:2009.

38. De Cacqueray, N., Bogey, C., Bailly, C., "Investigation of a High Mach Number Over-Expanded Jet Using LargeEddy Simulation," AIAA J, 49:10:2011.

39. Vourinen, V., Yu, J., Tirunagari, S., Kaario, O., Larmi, M., Duwig, C., Boersma, B.J., "Large-Eddy Simulation of Highly Under-Expanded Transient Gas Jets," Physics of Fluids, 25:016101:2013.

40. Scarcelli, R., Kastengren, A.L., Powel, C.F., Wallner, T., Matthias, N.S., "High-Pressure Gaseous Injection: A Comprehensive Analysis of Gas Dynamics and Mixing

Page 25 of 26
Effects," Proceedings of the Internal Combustion Engine Division, ASME-ICEF2012-92137.

41. Drozda, T. and Oefelein, J., "Large Eddy Simulation of Direct Injection Processes for Hydrogen and LTC Engine Applications," SAE Technical Paper 2008-01-0939, 2008.

42. Aleiferis, P.G., Rosati, M.F., "Controlled Autoignition of Hydrogen in a Direct-Injection Optical Engine," Combustion and Flame, 159:2500-2515:2012.

43. Malcolm, J., Behringer, M., Aleiferis, P.G., Mitcalf, J., OudeNijeweme, D., "Characterisation of Flow Structures in a Direct-Injection Spark-Ignition Engine Using PIV, LDV and CFD," SAE Technical Paper 2011-01-1290, 2011.

44. Launder, B.E., Spalding, D.B., "The Numerical Computation of Turbulent Flows," Computer Methods in Applied Mechanics and Engineering, 3:269-289:1974.

45. Smagorinsky, J., "General Circulation Experiments with the Primitive Equations," Monthly Weather Review, 91: 1963.

46. Butcher, A.J., Aleiferis, P.G., Richardson, D., "Development of a Real-Size Optical Injector Nozzle for Studies of Cavitation, Spray Formation and Flash Boiling at Conditions Relevant to Direct-Injection Spark-Ignition Engines," International Journal of Engine Research, in print.

47. Aleiferis, P.G, Serras-Pereira, J., van Romunde, Z., Caine, J., Wirth, M., "Mechanisms of Spray Formation and Combustion from a Multi-Hole Injector with E85 and Gasoline," Combustion and Flame, 157:735-756.

48. Chen, H., Zheng, J., Xu, P., Li, L., Liu, Y., Bie, H., "Study on Real-Gas Equations of High Pressure Hydrogen", Int. J. Hydrogen Energy, 35: 31003104:2010.

49. Nasrifar, K., "Comparative Study of Eleven Equations of State in Predicting the Thermodynamic Properties of Hydrogen," Int. J. Hydrogen Energy, 35:3802-3811:2010.

\section{ACKNOWLEDGMENTS}

The authors acknowledge the use of University College London's Legion High Performance Computing Facility (Legion@UCL), and associated support services, in the completion of this work. The CAD engine geometry is based on MAHLE Powertrain's single-cylinder optical research engine; use of this geometry for the scope of the current work is gratefully acknowledged. The authors would also like to thank all members of the UCL Internal Combustion Engines Group for their assistance and many useful discussions.

\section{ABBREVIATIONS}

AEOI After End Of Injection

ATDC After Top Dead Center

ASOI After Start of Injection 
BMEP Brake Mean Effective Pressure

CA Crank Angle Degree

CAD Computer-Aided Design

CFD Computational Fluid Dynamics

DI Direct Injection

DISI Direct Injection Spark Ignition

EGR Exhaust Gas Recirculation

EOI End of Injection

IVC Intake Valve Closure

LDV Laser Doppler Velocimetry

LES Large Eddy Simulation

PFI Port Fuel Injection

PIV Particle Image Velocimetry

PLIF Planar Laser Induced Fluorescence

RANS Reynolds-Averaged Navier-Stokes

RPM Revolution pre Minute

SI Spark Ignition

SOI Start of Injection

TDC Top Dead Center

\section{CONTACT}

Author for correspondence:

Dr. Pavlos Aleiferis

Department of Mechanical Engineering

University College London

Torrington Place

London WC1E 7JE

United Kingdom

E-mail: p.aleiferis@ucl.ac.uk

\section{$\underline{\text { SYMBOLS }}$}

$D \quad$ Nozzle Diameter

$X_{H 2} \quad$ Hydrogen Mole Fraction

$k \quad$ Turbulent Kinetic Energy

$M a \quad$ Mach Number

$P_{0} \quad$ Upstream Total Pressure

$P_{a} \quad$ Ambient Pressure

$T_{0} \quad$ Upstream Total Temperature

$T_{a} \quad$ Ambient Temperature

$\varepsilon \quad$ Dissipation Rate

$\lambda \quad$ Air Excess Ratio

$\phi \quad$ Equivalence Ratio 